\title{
Analysis of Monsoon Mission Coupled Forecasting System (MMCFS) model simulations of sub-division scale temperatures over India for the hot weather season (April-June)
}

\author{
Mahendra Benke ${ }^{1, *}$, Jasmine Takle ${ }^{1}$, D S Pai ${ }^{1}$ and Suryachandra A RaO ${ }^{2}$ \\ ${ }^{1}$ India Meteorological Department, Pune 411 005, India. \\ ${ }^{2}$ Indian Institute of Tropical Meteorology, Pune 411 008, India. \\ *Corresponding author.e-mail: mahendra_benke@hotmail.com
}

MS received 23 March 2018; revised 24 January 2019; accepted 10 February 2019; published online 1 July 2019

This study examines skill of the Monsoon Mission Climate Forecasting System (MMCFS) model simulations of monthly and seasonal maximum, minimum and mean temperatures of hot weather season (April, May and June) for the period 1982-2008 over India. The hindcast skill at the sub-division and all India scales were computed. The hindcasts were prepared using initial conditions (ICs) pertaining to January, February and March. The bias-corrected forecast for the 2016 AMJ season was also verified with the high resolution gridded temperature data of the India Meteorological Department (IMD). Standard verification skill scores, namely correlation coefficient (CC) and root mean square error (RMSE) have been used to assess the hindcast skill at various lead times. The grid point level statistical bias-correction was successful in reducing the bias and RMSE of the MMCFS model hindcast at the sub-division and all India scales. The hindcast analysis showed that for all the considered ICs and during all the months (April, May and June) and AMJ season for maximum, minimum and mean temperature bias of four sub-divisions Jammu \& Kashmir (J\&K), Himachal Pradesh, Uttarakhand, and Arunachal Pradesh showed bias $\leq-2.0^{\circ} \mathrm{C}$ and four sub-divisions Saurashtra and Kutch, Bihar, Gangetic West Bengal, Sub-Himalayan West Bengal (SHWB) and Sikkim showed bias $\geq 2{ }^{\circ} \mathrm{C}$. Hindcast based on the February and March ICs showed the best skill both in sub-division scale as well as in all India scale. Similarly, among the three months of the AMJ season, model skills based on considered ICs were best for the April month. Many of the sub-divisions from northwest India and neighboring central India and along the west coast showed significant hindcast skill for simulations based on February and March ICs. For the all India averaged temperature, March IC based forecast showed the highest skill for all the months and AMJ season followed by February IC. The MMCFS model forecasts for the 2016 monthly and seasonal temperatures were able to indicate correct signs of the observed temperature anomalies in most of the sub-divisions. The pattern anomaly correlations for the May and June forecasts based on March IC were significant at $\geq 95 \%$ level.

Keywords. Hot weather season (April-June) over India and sub-division; Monsoon Mission Coupled Forecasting System (MMCFS); temperature forecast; bias; RMSE; correlation coefficient and its significance.

Supplementary material pertaining to this article is available on the Journal of Earth System Science website (http://www. ias.ac.in/Journals/Journal_of_Earth_System_Science). 


\section{Introduction}

India, being in the tropics, many parts of the country experiences hot summers and relatively cooler winters. Country experiences hot weather during the period March to July with a maximum during the 3-month period of April-June (AMJ). During AMJ, many parts of the country experience heat wave conditions (a prolonged period of excessively hot weather) with summer temperatures routinely exceeding $40^{\circ} \mathrm{C}$ in many areas causing tremendous discomfort. As per the India Meteorological Department (IMD) records, highest ever temperature of $51^{\circ} \mathrm{C}$ in the country was recorded at Phalodi, Rajasthan on 20th May 2016. Consistent with the global warming trend (IPCC 2014), the all India annual mean temperature (figure 1) has also shown an increasing trend of $0.65^{\circ} \mathrm{C} / 100$ yrs during 1901-2016 (IMD 2017). During the same period, increasing trends of $1.06^{\circ} \mathrm{C} / 100$ yrs and $0.25^{\circ} \mathrm{C} / 100$ yrs were also seen in all India maximum and minimum temperatures (figures not shown).

Abnormally above normal temperatures can have devastating effects on human health, water resources and power generation resulting into the outage. There is a marked relationship between human mortality and thermal stress. Heat waves result in deaths due to heatstroke, heat exhaustion and heat cramps (Becker and Stewart 2011). In 2013, the death toll was 1433 in India due to heat waves. In 2014, the number fell to 549, while in 2015 heat wave took lives of 2,080 people (DWE Reports $2013,2014,2015)$. The recent research analysis also suggests increasing trends in the frequency and duration of heat waves over the country (Pai et al. 2013). A part of the increasing trend in the extreme temperature events can be attributed to increasing greenhouse gases due to anthropogenic activities (Pachauri et al. 2014). Kothawale et al. (2010) have also shown that positive anomalies of maximum and minimum temperatures are observed over India in the years following El Nino years. In the past, El Nino events over the Pacific are being associated with the increased heat wave conditions over the country (Pai et al. 2013).

In addition to the human aspects, a hot summer has also economic aspects. The electricity usage, mostly for air cooling/air conditioning purposes and for agriculture sharply spikes during the summer months (Valor et al. 2001; Sivakumar et al. 2005). A hotter than normal summer also increases the market demand for various cooling appliances (Filippini and Pachauri 2004). Various industries are sensitive to climatic variations. Hence for better planning and maximizing economic benefits, it is essential to provide forecasts of summer temperatures for India with sufficient lead time.

In India, though operational seasonal forecasting of rainfall was started almost 125 yrs ago, operational seasonal forecasting of temperature was first attempted only recently when IMD issued an operational temperature forecast for the 2016 hot weather season (April-June). The forecasts were prepared using state-of-the-art ocean-atmosphere coupled climate forecasting system (CFS) model implemented under the Monsoon Mission (MM)

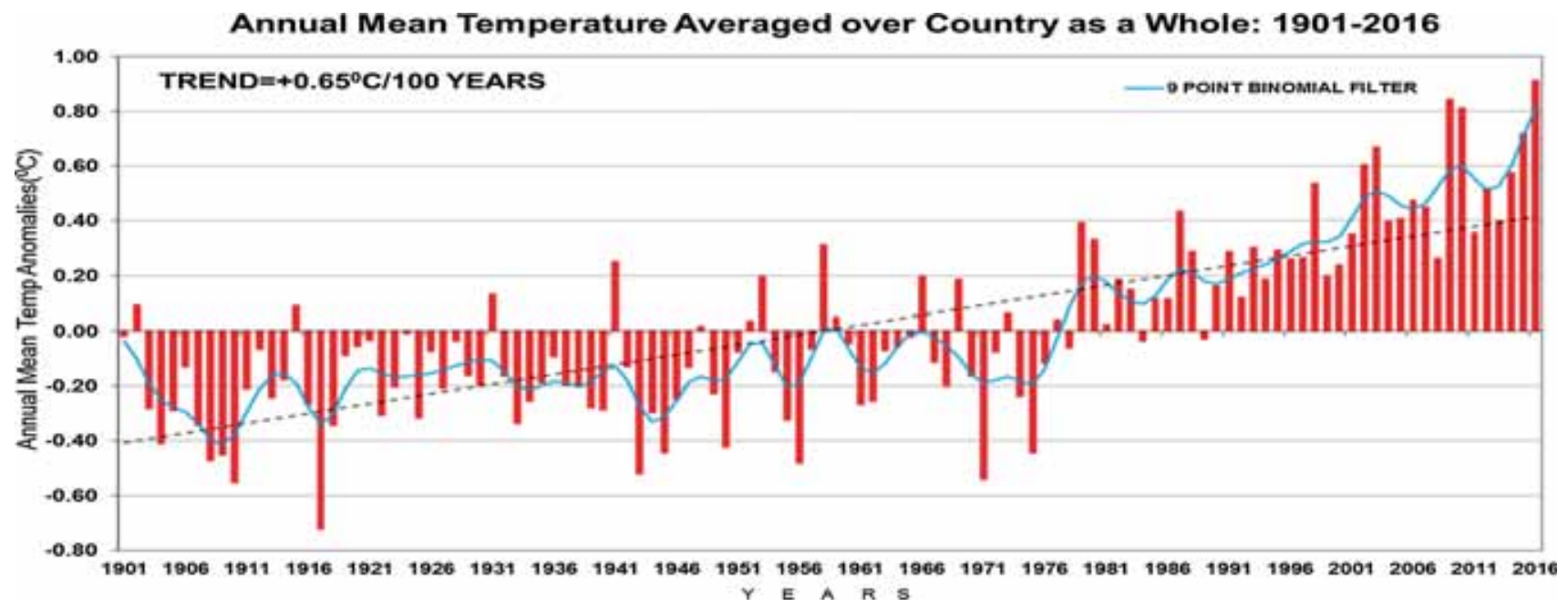

Figure 1. Annual mean land surface air temperatures anomalies averaged over India for the period 1901-2016. The anomalies were computed with respect to the base period of 1961-1990. The dotted line indicates the linear trend in the time series. The solid blue curve represents the sub-decadal time scale variation smoothed with a binomial filter. 
project launched by the Ministry of Earth Sciences (MoES) for generating monthly and seasonal forecasts for the monsoon rainfall over India and developed by the Indian Institute of Tropical Meteorology (IITM), Pune (Ramu et al. 2016). The basic modeling framework of Monsoon Mission climate forecasting system (hereafter referred as MMCFS) implemented by IITM was initially developed by the National Centres for Environmental Prediction (NCEP), USA as CFS model version 2 (CFSv2).

In general, all general circulations models (GCMs) as well as coupled GCMs (CGCMs) exhibit two types of errors in their outputs (FortmannRoe 2012). These are an error due to 'bias' or systematic error and error due to 'variance'. In spite of systematic improvements, the latest generation of CGCMs shows a general cold bias for temperature, and substantial precipitation biases, especially in the tropics. NCEP CFS and its higher resolution version MMCFS are not exceptions. This bias contributes to the poor skill of the model while forecasting and can be improved by applying bias-correction. However, a considerable reduction in the temperatures and rainfall biases were observed in the MMCFS resulting in better skill in the forecasting of All India Summer Monsoon Rainfall (AISMR) (Ramu et al. 2016).

The process of removing the systematic and variance error is generally known as bias-correction or bias adjustment. For bias-correction in models, two types of downscaling approaches; physical process based dynamic downscaling and statistically based approach (Maurer and Hidalgo 2008). Statistical downscaling approach requires the lower computational requirement compared to the dynamical model-based alternative, and thus, statistical downscaling approaches are widely used in climate impact-related research work (Wood et al. 2004; Ines and Hansen 2006; Cayan et al. 2008; Maurer and Hidalgo 2008; Li et al. 2010; Piani et al. 2010). Statistical bias-correction involves the establishment of a statistical relationship or transfer function derived from observations and model outputs (i.e., hindcasts) based on available historical datasets and then apply the established transfer function to model outputs (hindcasts and forecasts) to obtain bias corrected model outputs.

\section{Data and methodology}

The data used in this study were the monthly averaged 2 meter temperature(maximum,minimum and mean) over Indian main land simulated by the MMCFS. However, for this study, monthly hindcasts for the hot weather season (AMJ) were made using initial conditions of 00 and 12 UTC. The hindcasts with respective three different lead times (0-2 months) were used (i.e., hindcasts corresponding to initial conditions (ICs) during January to March of the reference year). For generating the 2016 monthly forecast for the AMJ season, more than 40 ensemble members corresponding to each monthly initial condition (IC) (Jan IC-47, Feb IC-49 and Mar IC-66 ensemble members) were used. IMD high resolution $\left(0.5^{\circ} \times 0.5^{\circ}\right)$ daily gridded temperature (maximum, minimum and mean) data (Srivastava et al. 2009) for the AMJ season for the period of $1982-$ 2008 and 2016. Both the observed and model data were re-gridded to $0.25^{\circ} \times 0.25^{\circ}$ spatial resolution.

The observed and model monthly gridded (maximum, minimum and mean) data were used to compute area weighted sub-division temperature average for the all the 34 sub-divisions of Indian main land. Sub-divisions considered are as shown in the supplementary figure 1S. The two island sub-divisions were not considered in this study as the observed gridded temperature data over these two sub-divisions are not available in the original dataset. It is worth mentioning that there is some scarcity of observed station temperature data in sub-divisions like Arunachal Pradesh, Nagaland, Manipur, Mizoram and Tripura (NMMT) and Jammu \& Kashmir (J\&K).

In this study, we have used the quantile-based mapping method (Panofsky and Brier 1958) for the bias-correction of MMCFS monthly temperature data. A simple illustration of statistical bias-correction methodology of mapping the model distribution of temperature at a gird point to the observation at the same grid point is shown in supplementary figure S2. This method is a relatively simple and maps the cumulative distribution function (CDF) or probability distribution functions (PDFs) of monthly gridded model temperatures onto that of gridded observed data. The design of the method is such that it adjusts all the moments of the specific variable. For a climate variable ' $x$ ' at a given grid point, the equation used for computing bias-corrected (bc) model data $\left(x_{\text {mod }}\right)$ derived in this method can be written as

$$
\left(x_{\text {mod }}\right)_{\mathrm{bc}}=c d f_{\mathrm{obs}, \mathrm{h}}^{-1}\left(c d f_{\bmod , \mathrm{h}}\left(x_{\text {mod }}\right)\right)
$$


Bias of MMCFS Hindcast With IMD Observed Maximum Temperature(1982-2008)
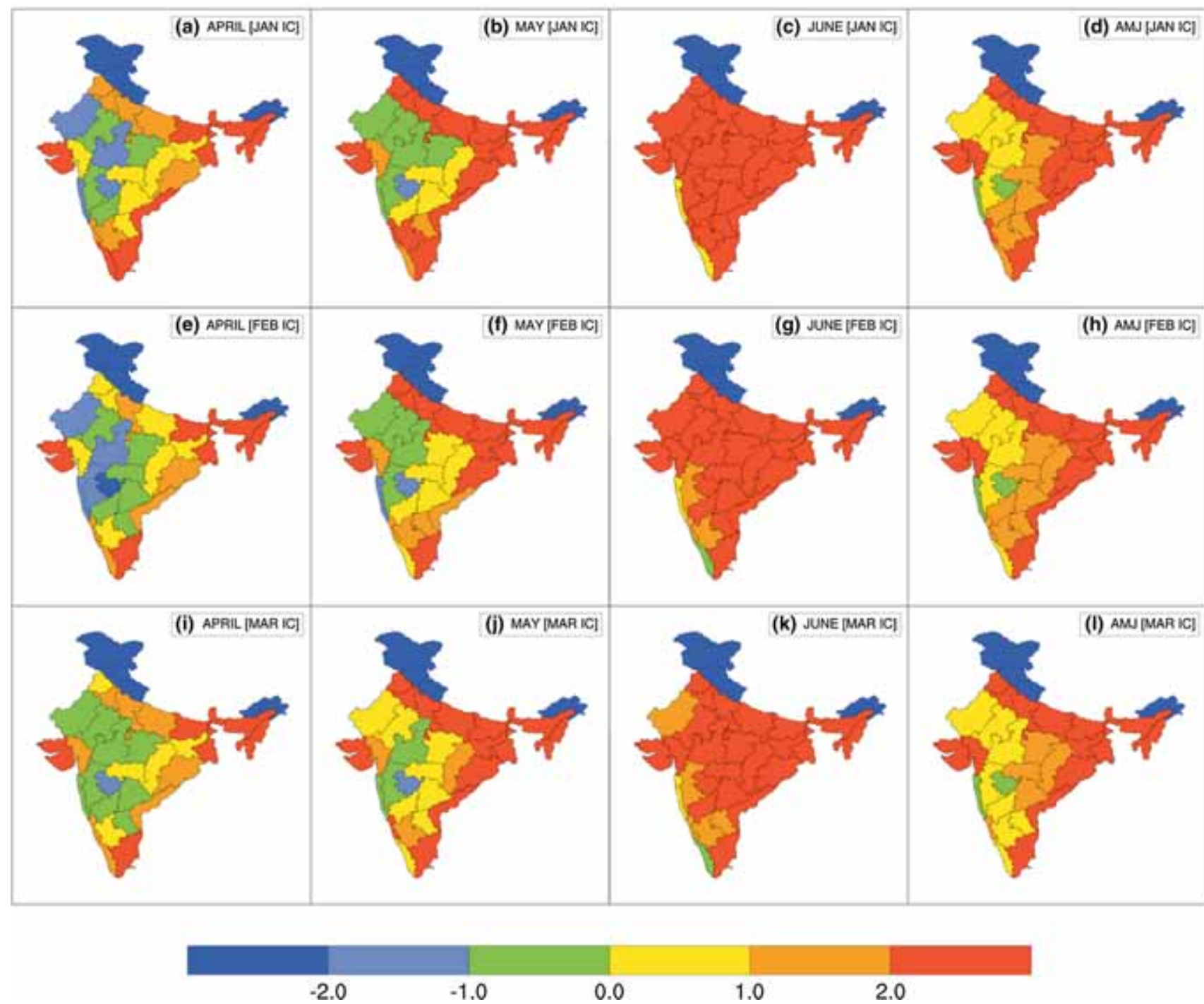

Figure 2. Maximum temperature bias (in ${ }^{\circ} \mathrm{C}$ ) seen in MMCFS model when compared with IMD observed values using January initial condition for April, May, June and AMJ season as a whole discussed in the first row and similarly using February and March initial conditions in 2nd and 3rd, rows respectively.

where $c d f_{\text {obs }}\left(c d f_{\text {mod }}\right)$ is the CDF of the observed (model) data of variable ' $x$ ' at that gird point during the hindcast period $(h) . x_{\bmod }$ represents hindcast/forecast model data at the grid point.

The skill statistics such as correlation coefficient (CC) between root mean squared error (RMSE), and bias (BIAS) of the MMCFS model on sub-division and all India averaged scale for the monthly and seasonal temperatures (maximum, minimum and mean) for the AMJ season were computed for the hindcast period (1982-2008) using January, February and March initial conditions. The skill statistics were computed for before and after bias-corrected data and compared. The bias-corrected anomaly forecast for the monthly and seasonal sub-division averaged and all India temperatures for the 2016 AMJ season were also verified.

\section{Results and discussions}

\subsection{Hindcast skill statistics of MMCFS sub-division averaged monthly and seasonal temperatures}

\subsubsection{Maximum temperature}

Figure 2 shows the model bias in the sub-division averaged maximum temperature over India from the IMD observed maximum temperature 
RMSE of MMCFS Hindcast With IMD Observed Maximum Temperature (1982-2008)
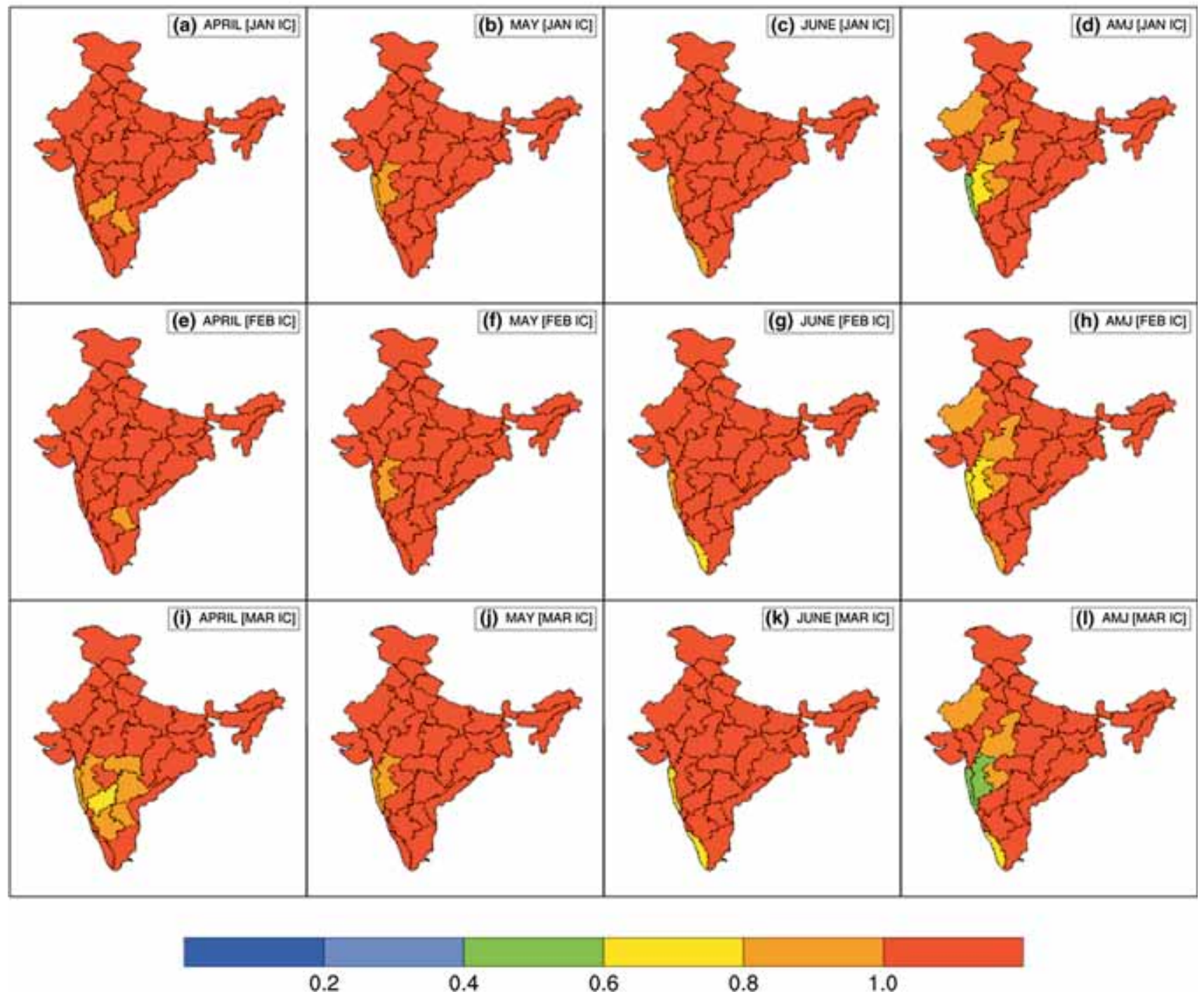

Figure 3. Maximum temperature RMSE (in ${ }^{\circ} \mathrm{C}$ ) before bias-correction seen in MMCFS model when compared with IMD observed values using January initial condition for April, May, June and AMJ season as a whole discussed in the first row and similarly using February and March initial conditions in 2nd and 3rd last rows, respectively.

computed for the hindcast period (1982-2008) before applying statistical bias-correction. In figure 2 , it is seen that for all the ICs considered and during all the months and AMJ season, four subdivisions, viz., J\&K, Himachal Pradesh, Uttarakhand, and Arunachal Pradesh showed bias $\leq-2{ }^{\circ} \mathrm{C}$ and sub-divisions, viz., Saurashtra and Kutch, Tamil Nadu and Puducherry, Bihar, Gangetic West Bengal, Sub-Himalayan West Bengal (SHWB) and Sikkim, Assam and Meghalaya and NMMT showed bias $\geq 2^{\circ} \mathrm{C}$. All considered IC's show negative bias in west and east Rajasthan, west and east Madhya Pradesh, Konkan and Goa, Madhya Maharashtra, and Marathwada during the April month (figure 2a, e and i), west Madhya Pradesh, Konkan and Goa, Madhya
Maharashtra and Marathwada during the May month (figure 2b, f and j), Konkan and Goa and Marathwada for the AMJ season (figure $2 \mathrm{~d}$, $\mathrm{h}$ and 1). Remaining sub-divisions corresponding to all the ICs show positive bias with many of these sub-divisions for April, May, June months and AMJ season (figure $2 \mathrm{a}-\mathrm{l}$ ). It was observed that for most of the sub-divisions after bias-correction, the biases were within $\pm 0.1^{\circ} \mathrm{C}$ for maximum temperature indicating that the methodology used was successful in correcting the bias (map is not presented here). However, there is an exception in Arunachal Pradesh where bias $\geq 2.0^{\circ} \mathrm{C}$ is observed.

Figure 3 shows RMSE of sub-division averaged maximum temperature before bias-correction, 
RMSE of MMCFS Hindcast With IMD Observed Maximum Temperature (1982-2008) After Statistical Bias Correction
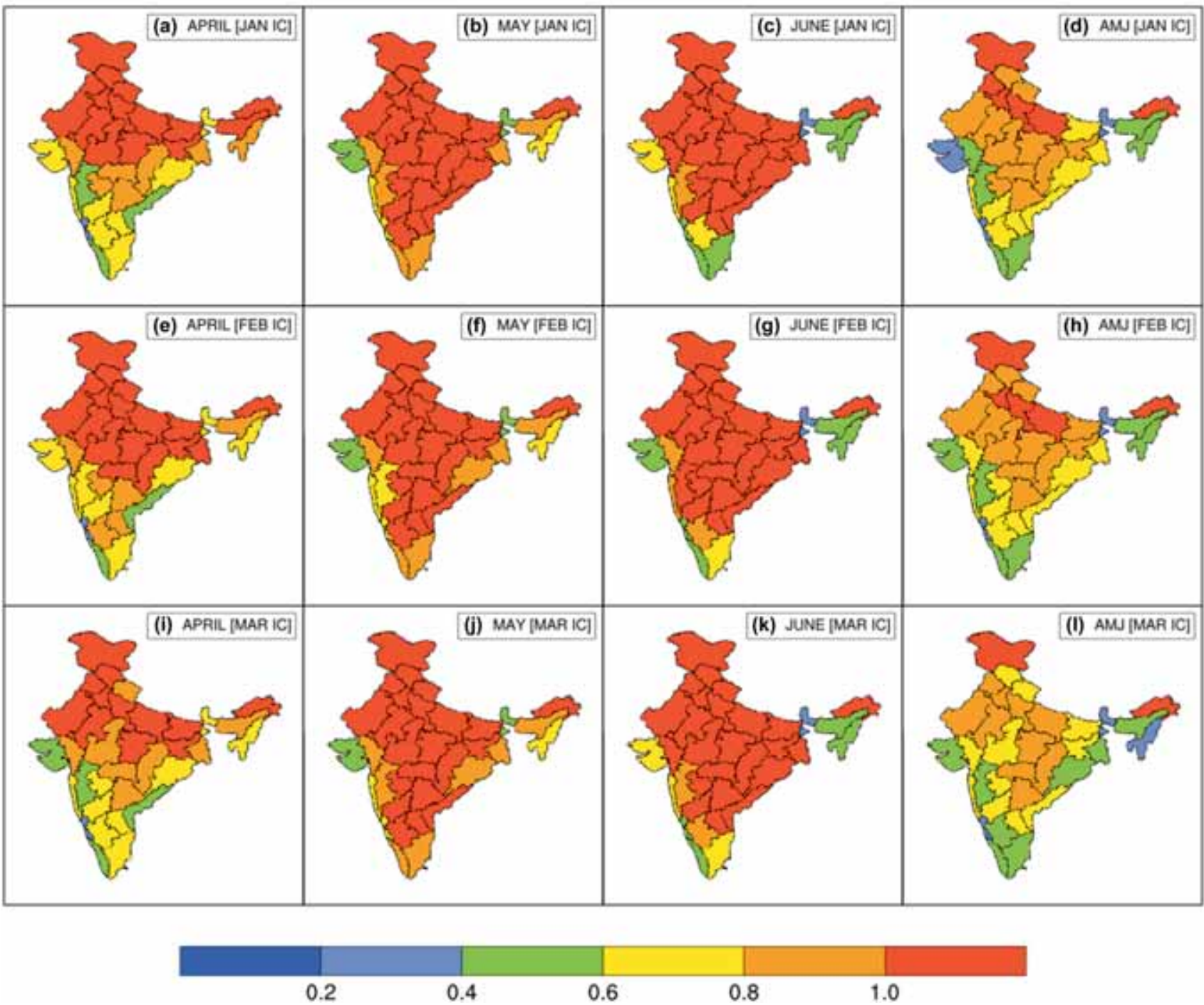

Figure 4. Maximum temperature RMSE (in ${ }^{\circ} \mathrm{C}$ ) after bias-correction seen in MMCFS model when compared with IMD observed values using January initial condition for April, May, June and AMJ season as a whole discussed in the first row and similarly using February and March initial conditions in 2nd and 3rd rows, respectively.

computed for the hindcast period (1982-2008). In this figure, it is seen that during all the months and the AMJ season, the RMSE is $\geq 1^{\circ} \mathrm{C}$ in most of the sub-divisions. Figure 4, is same as figure 3 but for bias-corrected maximum temperature RMSE. In figure 4, it is seen that there is a slight decrease in the RMSE after biascorrection particularly in April month and AMJ season and for sub-divisions from south peninsula (particularly from the coastal region) and northeast India. After statistical bias-correction in figure 4, there is a noticeable decrease in the RMSE (exception is J\&K and Arunachal Pradesh for all cases) particularly in June month and AMJ season and for sub-divisions from south peninsula (particularly from the coastal region) and northeast India.

Figure 5 shows $\mathrm{CC}$ between the sub-division averaged observed and model maximum temperatures for the hindcast period (1982-2008) for both with and without model bias-correction were prepared. However, there was little difference seen before and after bias-correction. Therefore, here we have presented only the CC map of observed and bias-corrected maximum temperatures. In the map, CC values of $0.32,0.38$ and 0.45 corresponding to significant levels of 90, 95 and $99 \%$, respectively have been used for shading. Sub-divisions with negative CC are not shaded. Sub-divisions showing significant CC at $\geq 95 \%$ 


\section{Correlation Coefficient Of MMCFS Hindcast and IMD Observed Maximum Temperature (1982-2008)}
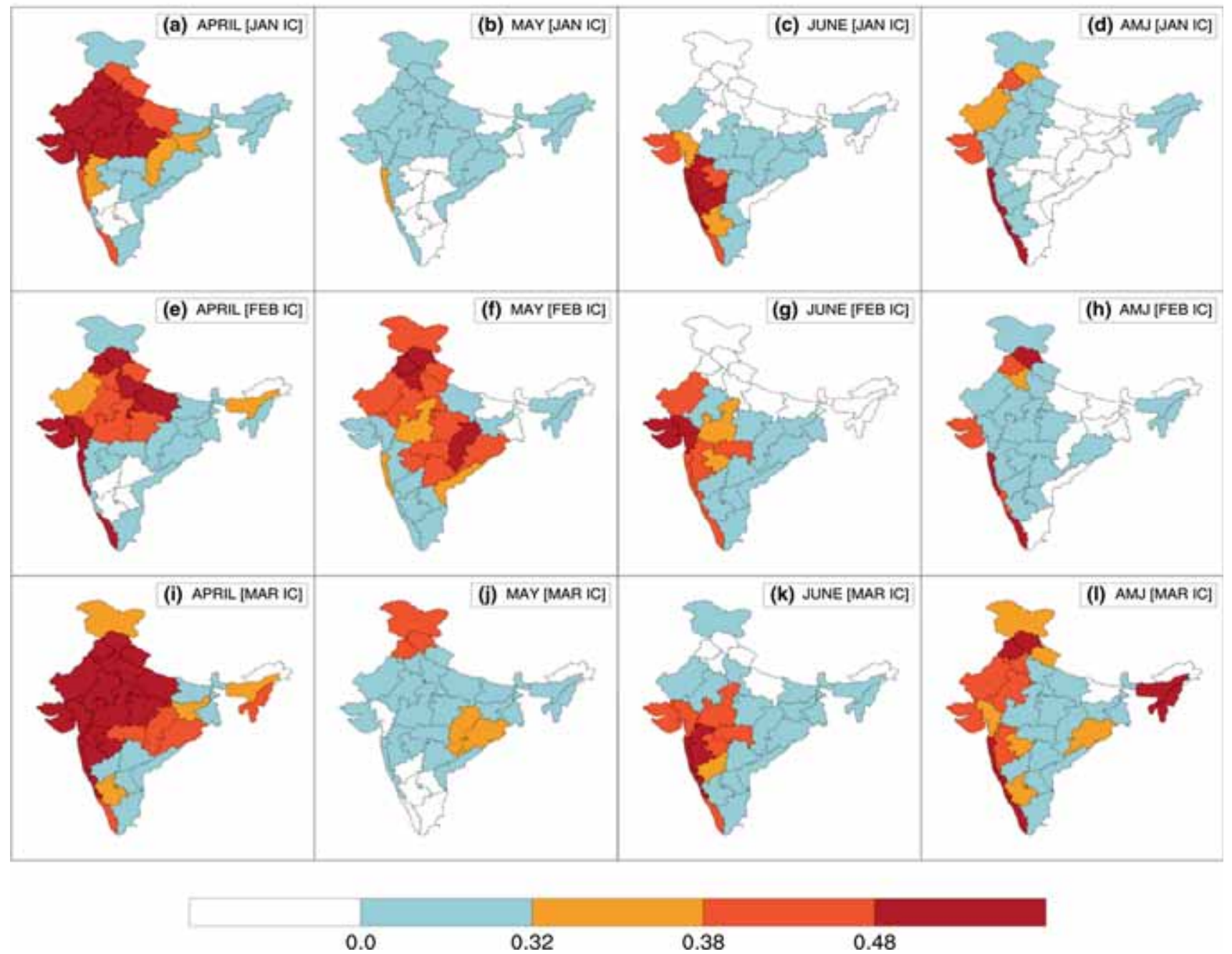

Figure 5. Maximum temperature CC (colours indicating white: negative CC, blue: positive less than $90 \%$ level of significance, yellow: positive 90-95\% level of significance, red: positive 95-99\% level of significance and dark red: positive 99\% and above level of significance) of MMCFS with IMD observed for April, May, June months and AMJ season as a whole shown column wise, respectively using January, February and March IC.

level for April month (figure 5a, e and i) go on increasing with decrease in lead time from January IC to March IC in which March IC shows significant $\mathrm{CC}$ at $\geq 95 \%$ level at Kerala, Konkan and Goa, Chhattisgarh, Jharkhand, J\&K, Delhi, Haryana and Chandigarh, Punjab, Uttaranchal, Himachal Pradesh, west Uttar Pradesh, and sub-divisions of Gujarat, Maharashtra, Rajasthan, and Madhya Pradesh. For May month (figure $5 \mathrm{~b}$, $\mathrm{f}$ and $\mathrm{j}$ ) significant $\mathrm{CC}$ at $\geq 95 \%$ level is seen at northern, central and east coast (excluding peninsula) sub-divisions using February IC. West Indian sub-divisions show significant $\mathrm{CC}$ at $\geq 95 \%$ level for June month (figure 5c, g and k) using all ICs considered. For AMJ season as a whole, March IC shows significant CC at $\geq 95 \%$ level over J\&K, Himachal Pradesh, Haryana, Delhi and Chandigarh, Punjab, Uttaranchal, subdivisions of Rajasthan and Gujarat, Konkan and Goa, Marathwada, Madhya Maharashtra, Kerala, coastal Karnataka and South Interior Karnataka (SIK).

\subsubsection{Minimum temperature}

Figure 6 shows the model bias before correction in the sub-division averaged minimum temperature over India from the IMD observed minimum temperature computed for the hindcast period (1982-2008). In figure 6, it is seen that for all the ICs considered and during all the months and AMJ season, four sub-divisions, viz., J\&K, 
Bias of MMCFS Hindcast With IMD Observed Minimum Temperature(1982-2008)
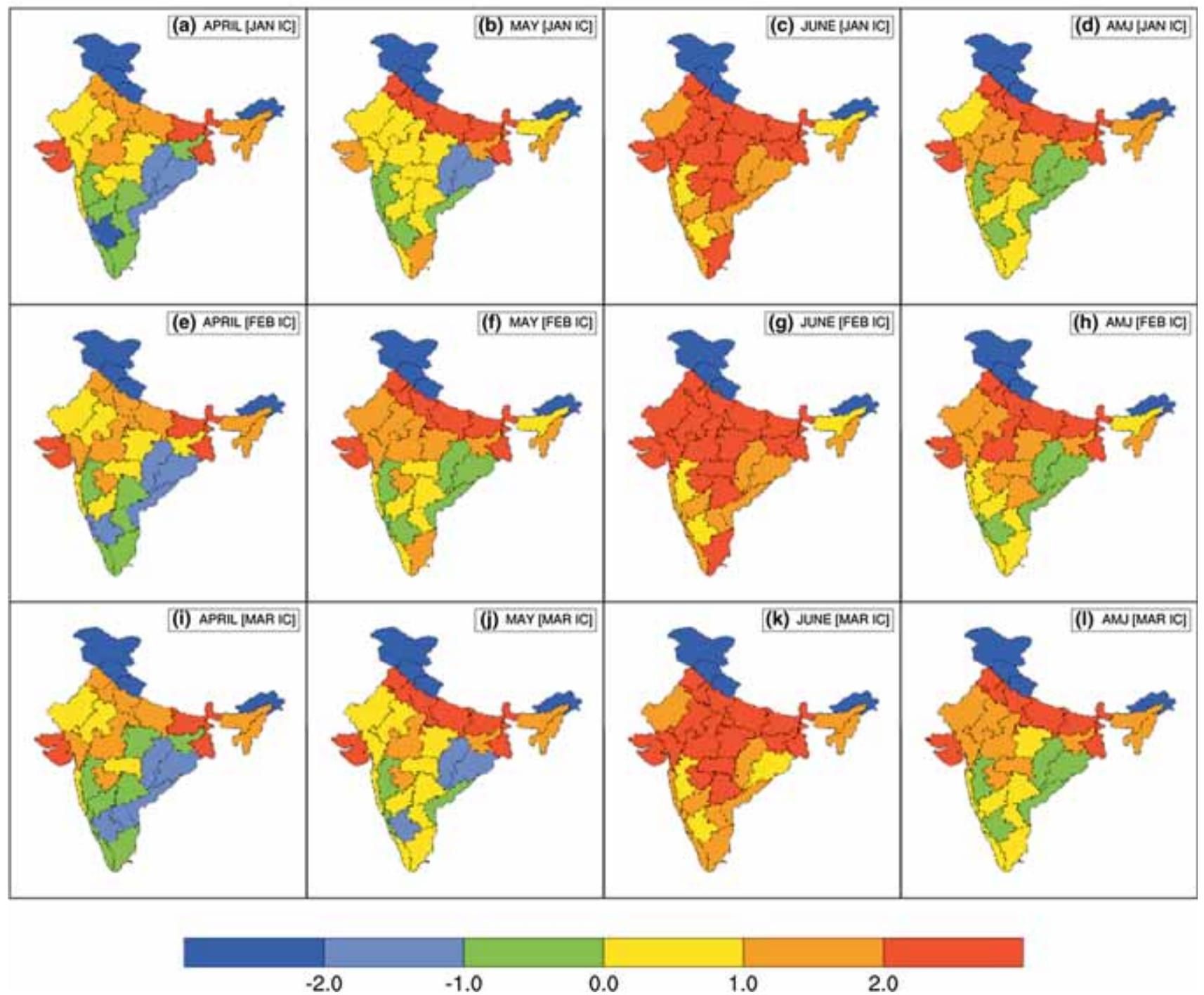

Figure 6. Minimum temperature bias (in ${ }^{\circ} \mathrm{C}$ ) seen in MMCFS model when compared with IMD observed values using January initial condition for April, May, June and AMJ season as a whole discussed in the first row and similarly using February and March initial conditions in 2nd and 3rd rows, respectively.

Himachal Pradesh, Uttarakhand, and Arunachal Pradesh showed bias $\leq-2^{\circ} \mathrm{C}$.

All considered IC's show negative bias of 0 to $-2.0^{\circ} \mathrm{C}$ in sub-divisions like Madhya Maharashtra, coastal Karnataka, South Interior Karnataka (SIK), Tamil Nadu and Puducherry, Rayalaseema, coastal Andhra Pradesh, Odisha, Kerala and Chhattisgarh for April month (figure 6a, e and i) and the sub-divisions coastal Andhra Pradesh, Odisha, Chhattisgarh and SIK for May month (figure 6b, f and j) and coastal Andhra Pradesh and SIK for AMJ season (figure $6 \mathrm{~d}, \mathrm{~h}$ and $\mathrm{l}$ ). Remaining sub-divisions(figure 6) corresponding to allthe ICs show positive bias with many of these sub-divisionsshowing bias of $\geq 1{ }^{\circ} \mathrm{C}$ particularly those along theplains of Himalayas (from Punjabto Gangetic West Bengal) and Gujarat, Saurashtra and Kutch from west India for April, May, June months and AMJ season. It was observed that for most of the sub-divisions after bias-correction, the biases were within $\pm 0.1^{\circ} \mathrm{C}$ for minimum temperatures indicating that the methodology used was successful in correcting the bias(map is not presented here). However, there is an exception in Arunachal Pradesh where bias $\geq 2.0^{\circ} \mathrm{C}$ is observed.

Figure 7 shows RMSE of sub-division averaged minimum temperatures before bias-correction, computed for the hindcast period (1982-2008). In this figure, it is seen that during all the months 
RMSE of MMCFS Hindcast With IMD Observed Minimum Temperature (1982-2008)
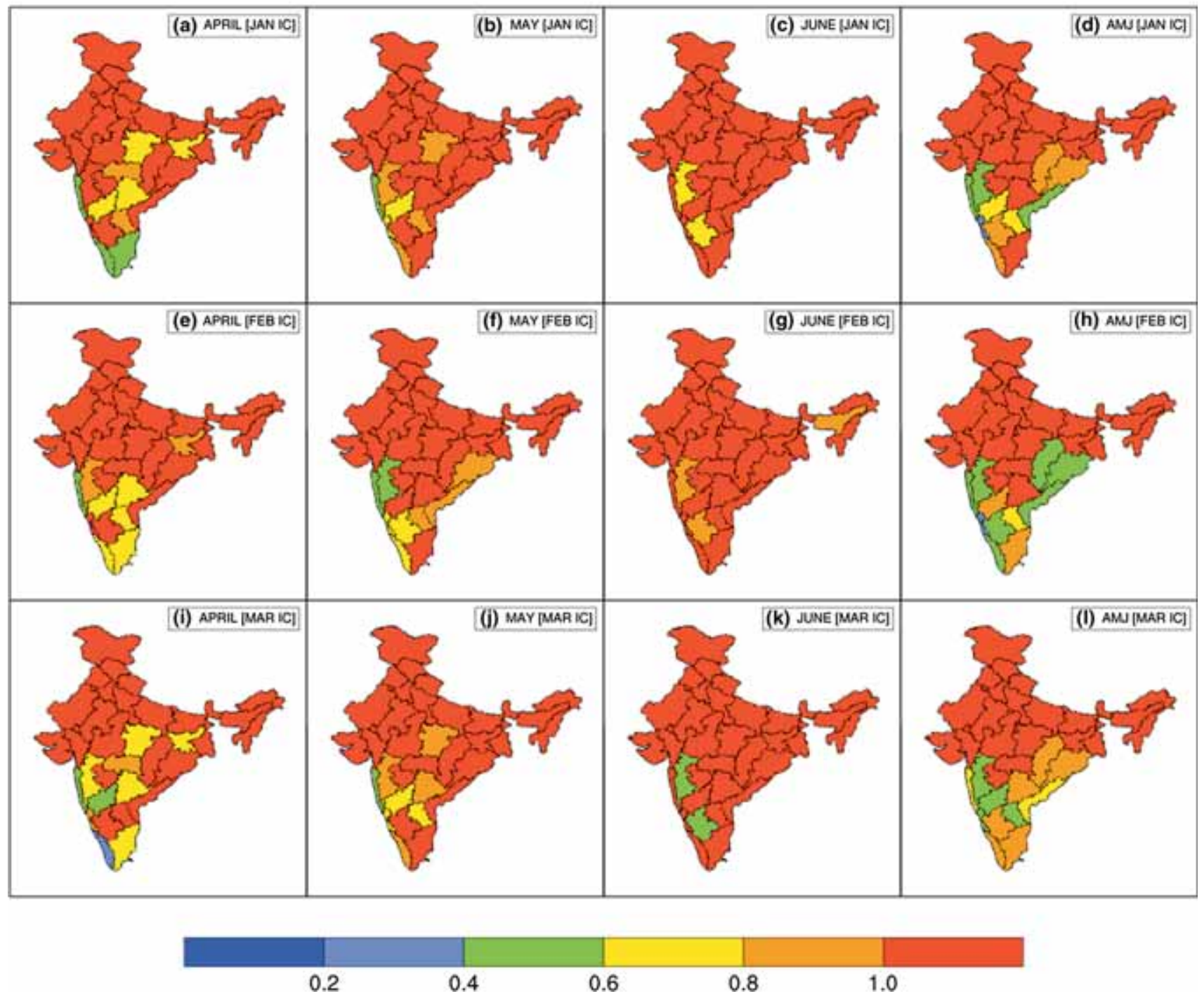

Figure 7. Minimum temperature RMSE (in ${ }^{\circ} \mathrm{C}$ ) before bias-correction seen in MMCFS model when compared with IMD observed values using January initial condition for April, May, June and AMJ season as a whole discussed in the first row and similarly using February and March initial conditions in 2nd and 3rd rows, respectively.

and the AMJ season, the RMSE is $\geq 1^{\circ} \mathrm{C}$ in most of the sub-divisions. Figure 8 is same as figure 7 , but for bias-corrected minimum temperature RMSE. In figure 8 , it is seen that there is a slight decrease in the RMSE after bias-correction particularly in the April month and AMJ season and for sub-divisions from south Peninsula (particularly from the coastal region) and northeast India for all months and season except J\&K and Arunachal Pradesh.

$\mathrm{CC}$ between the sub-division averaged observed and model minimum temperature for the hindcast period (1982-2008) for both with and without model bias-correction were prepared. However, there was little difference seen before and after bias-correction. Therefore, here we have presented only the CC map of observed and bias-corrected minimum temperature (figure 9). In the map, CC values of $0.32,0.38$ and 0.45 corresponding to significant levels of 90,95 and $99 \%$, respectively have been used for shading. Sub-divisions with negative CC are not shaded. For April month compared to January and February ICs, March IC shows significant CC at $\geq 95 \%$ level over most of the subdivisions excluding Arunachal Pradesh, Odisha, Chhattisgarh, coastal Andhra Pradesh, Kerala, Tamil Nadu and Puducherry and west Rajasthan. For the May month (figure $9 \mathrm{~b}, \mathrm{f}$ and $\mathrm{j}$ ) though significant CC at $\geq 99 \%$ level is seen over Jharkhand using January IC and sub-divisions like SubHimalayan West Bengal and Sikkim (henceforth 
RMSE of MMCFS Hindcast With IMD Observed Minimum Temperature (1982-2008) After Statistical Bias Correction
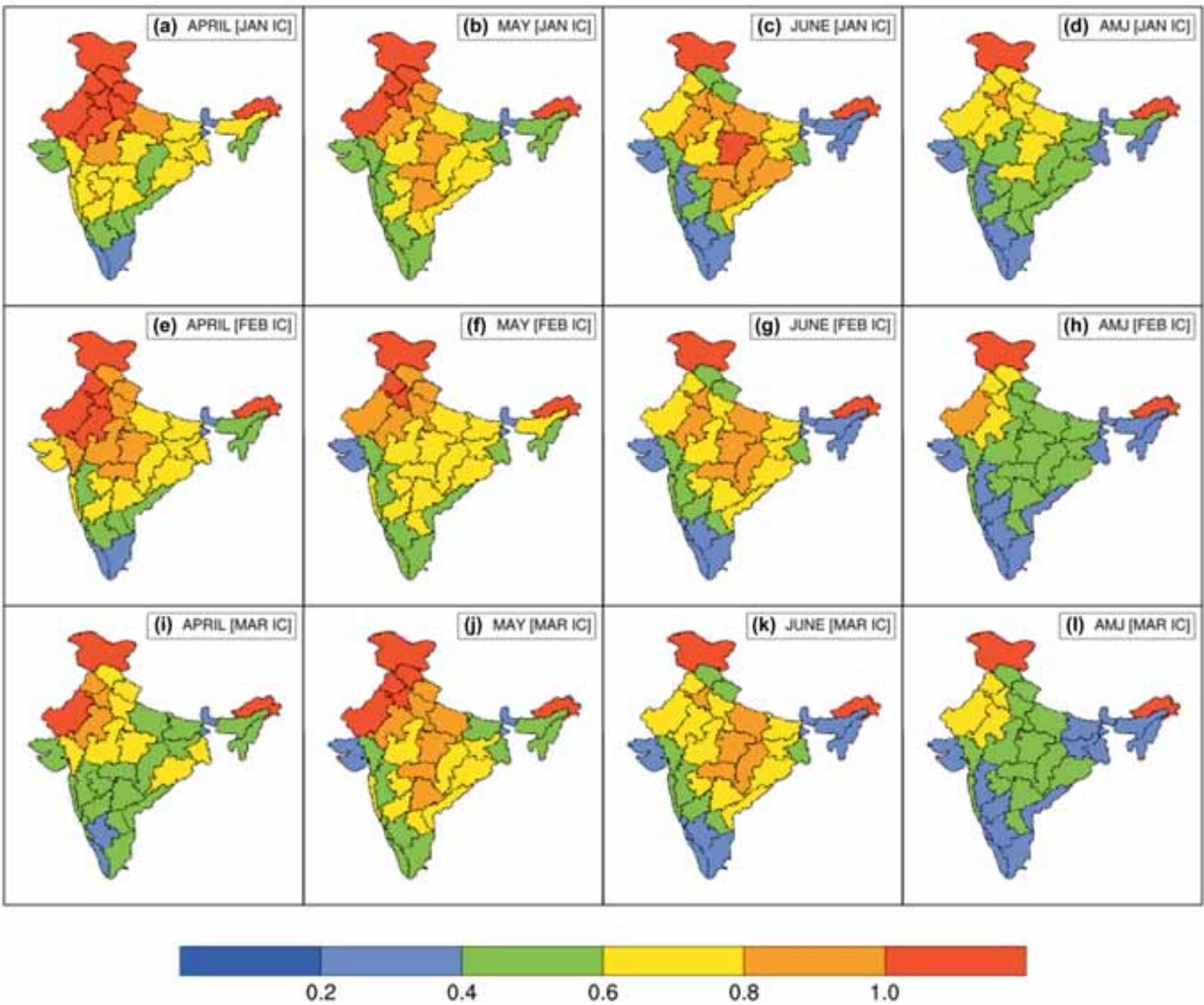

Figure 8. Minimum temperature RMSE (in ${ }^{\circ} \mathrm{C}$ ) after bias-correction seen in MMCFS model when compared with IMD observed values using January initial condition for April, May, June and AMJ season as a whole discussed in the first row and similarly using February and March initial conditions in 2nd and 3rd rows, respectively.

SHWB and Sikkim) and Gujarat region using March IC, it is the February IC, which covers most of the sub-divisions with significant $\mathrm{CC}$ at $\geq 99 \%$ level, i.e., northern and central region subdivisions. For June month (figure $9 \mathrm{c}, \mathrm{g}$ and $\mathrm{k}$ ) using January IC significant CC at $\geq 95 \%$ level is seen over Konkan and Goa, Marathwada, Madhya Maharashtra, North Interior Karnataka (NIK), SIK, coastal Karnataka and Kerala, remaining two ICs show significant CC at $\geq 95 \%$ level over the same sub-divisions discussed for January IC with Himachal Pradesh, Punjab, Gujarat region, Saurashtra and Kutch, SHWB and Sikkim for February IC and west Madhya Pradesh, Himachal
Pradesh, J\&K and SHWB and Sikkim for March IC. For AMJ season (figure 9d, h and l) March IC shows significant CC at $\geq 95 \%$ level over northern, north-eastern (excluding Arunachal Pradesh and Jharkhand), sub-divisions of Gujarat and Maharashtra, west Madhya Pradesh, North \& South Interior Karnataka and Kerala.

\subsubsection{Mean temperature}

Figure 10 shows the model bias before statistical correction in the sub-division averaged mean temperature over India from the IMD observed mean temperature computed for the hindcast period 
Correlation Coefficient Of MMCFS Hindcast and IMD Observed Minimum Temperature (1982-2008)
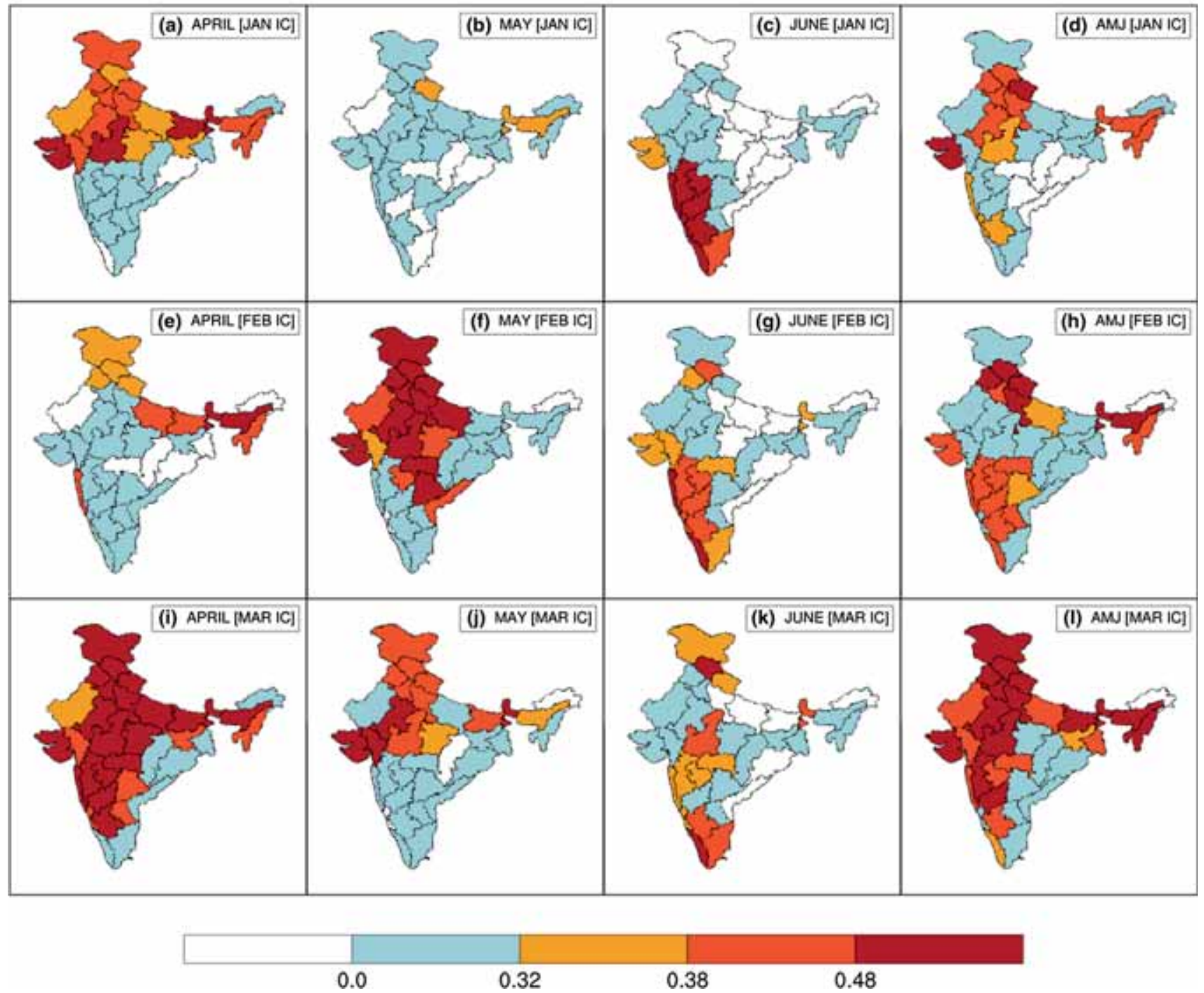

Figure 9. Minimum temperature CC (colours indicating white: negative CC, blue: positive less than $90 \%$ level of significance, yellow: positive 90-95\% level of significance, red: positive 95-99\% level of significance and dark red: positive 99\% and above level of significance) of MMCFS with IMD observed for April, May, June months and AMJ season as a whole shown column wise, respectively using January, February and March IC.

(1982-2008). In figure 10, it is seen that for all the ICs considered and during all the months and AMJ season, four sub-divisions, viz., J\&K, Himachal Pradesh, Uttarakhand, and Arunachal Pradesh showed bias $\leq-2^{\circ} \mathrm{C}$ and sub-divisions, viz., Saurashtra and Kutch, Bihar, Gangetic West Bengal, SHWB and Sikkim, Assam and Meghalaya and NMMT showed bias $\geq 2{ }^{\circ} \mathrm{C}$.

For the April month (figure 10a, e and i), negative bias from 0 to $-1.0^{\circ} \mathrm{C}$ is seen over sub-divisions of Rajasthan, east Madhya Pradesh (using January IC), Madhya Maharashtra, Marathwada, SIK, Chhattisgarh (using all three ICs), Rayalaseema (using January and March IC), Konkan and Goa (using January and February IC) and NIK. Remaining sub-divisions show positive bias. For the May month (figure 10b, f and j), Konkan and Goa (using all three ICs), Madhya Maharashtra (using January and March IC) and Chhattisgarh (using January IC) show negative bias from 0 to $-1.0^{\circ} \mathrm{C}$, while other sub-divisions show positive bias. For the June month (figure 10c, $\mathrm{g}$ and $\mathrm{k}$ ) and AMJ season (figure $10 \mathrm{~d}, \mathrm{~h}$ and l) using all three ICs the sub-divisions show positive bias. It was observed that for most of the sub-divisions after bias-correction, the biases were within $\pm 0.1^{\circ} \mathrm{C}$ for mean temperatures indicating that the methodology used was 
Bias of MMCFS Hindcast With IMD Observed Mean Temperature(1982-2008)

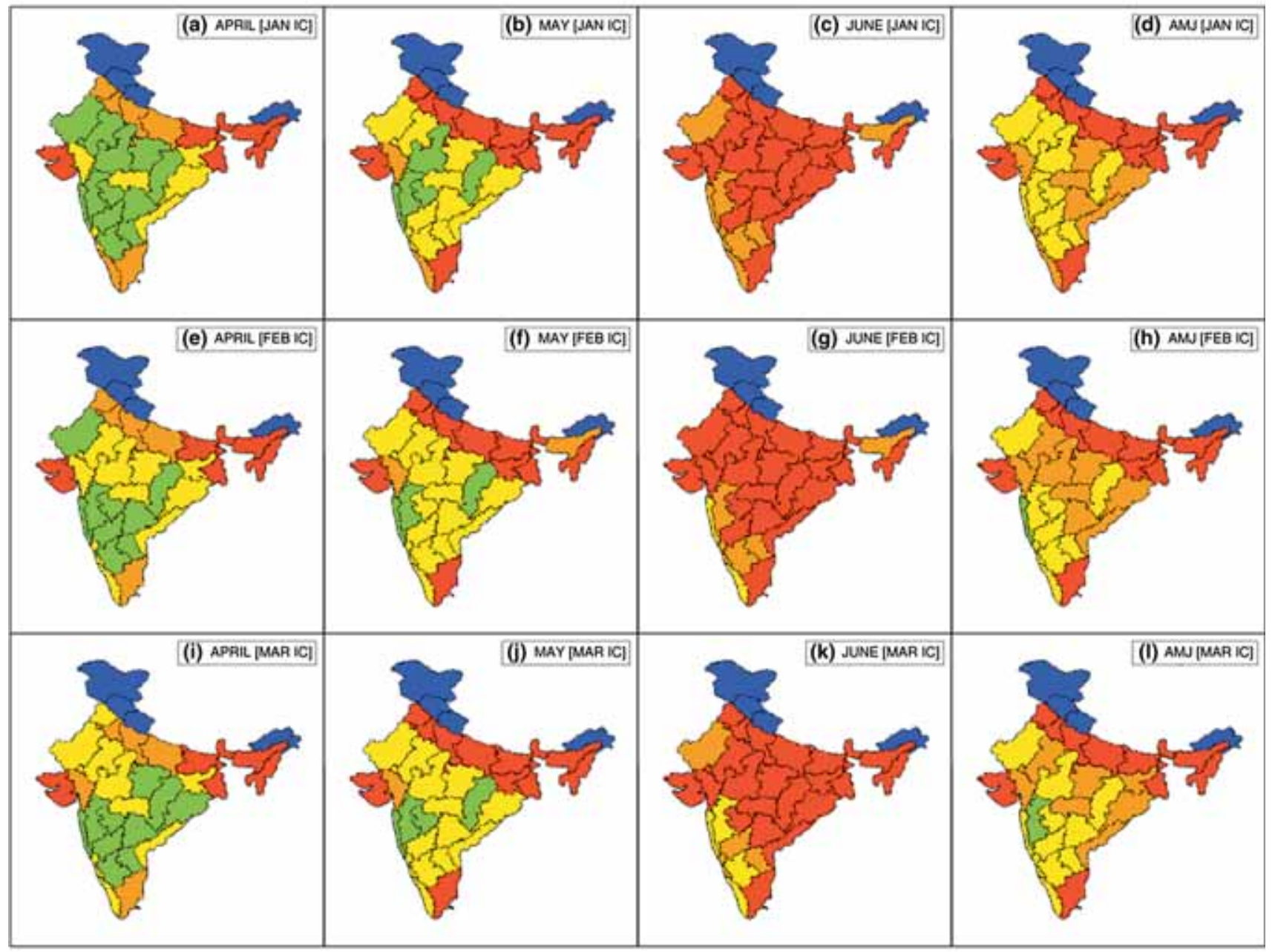

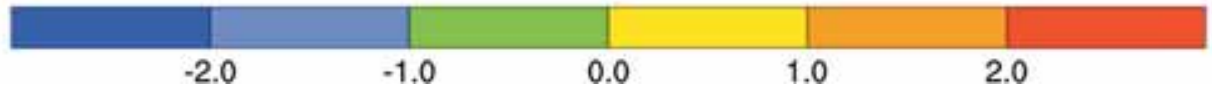

Figure 10. Mean temperature bias (in ${ }^{\circ} \mathrm{C}$ ) seen in MMCFS model when compared with IMD observed values using January initial condition for April, May, June and AMJ season as a whole discussed in the first row and similarly using February and March initial conditions in 2nd and 3rd rows, respectively.

successful in correcting the bias (map is not presented here). However, there is an exception in Arunachal Pradesh, where bias $\geq 2.0^{\circ} \mathrm{C}$ is observed.

Figure 11 shows RMSE before bias-correction of sub-division averaged mean temperatures, computed for the hindcast period (1982-2008). In this figure, it is seen that during all the months and the AMJ season, the RMSE is $\geq 1{ }^{\circ} \mathrm{C}$ in most of the sub-divisions. Figure 12 is same as figure 11, but for bias-corrected mean temperature RMSE. In figure 12 it is seen that there is a slight decrease in the RMSE after bias-correction (exception is J\&K and Arunachal Pradesh for all cases). In all months and AMJ season sub-divisions from south peninsula (particularly from the coastal region) and northeast India show less RMSE after bias-correction.

CC between the sub-division averaged observed and model mean temperatures for the hindcast period (1982-2008) for both with and without model bias-correction were prepared. However, there was little difference seen before and after bias-correction. Therefore, here we have presented only the CC map of observed and bias-corrected mean temperature (figure 13). In the map, CC values of $0.32,0.38$ and 0.45 corresponding to significant levels of 90, 95 and $99 \%$, respectively have been used for shading. Sub-divisions with negative $\mathrm{CC}$ are not shaded. For the April month 
RMSE of MMCFS Hindcast With IMD Observed Mean Temperature (1982-2008)

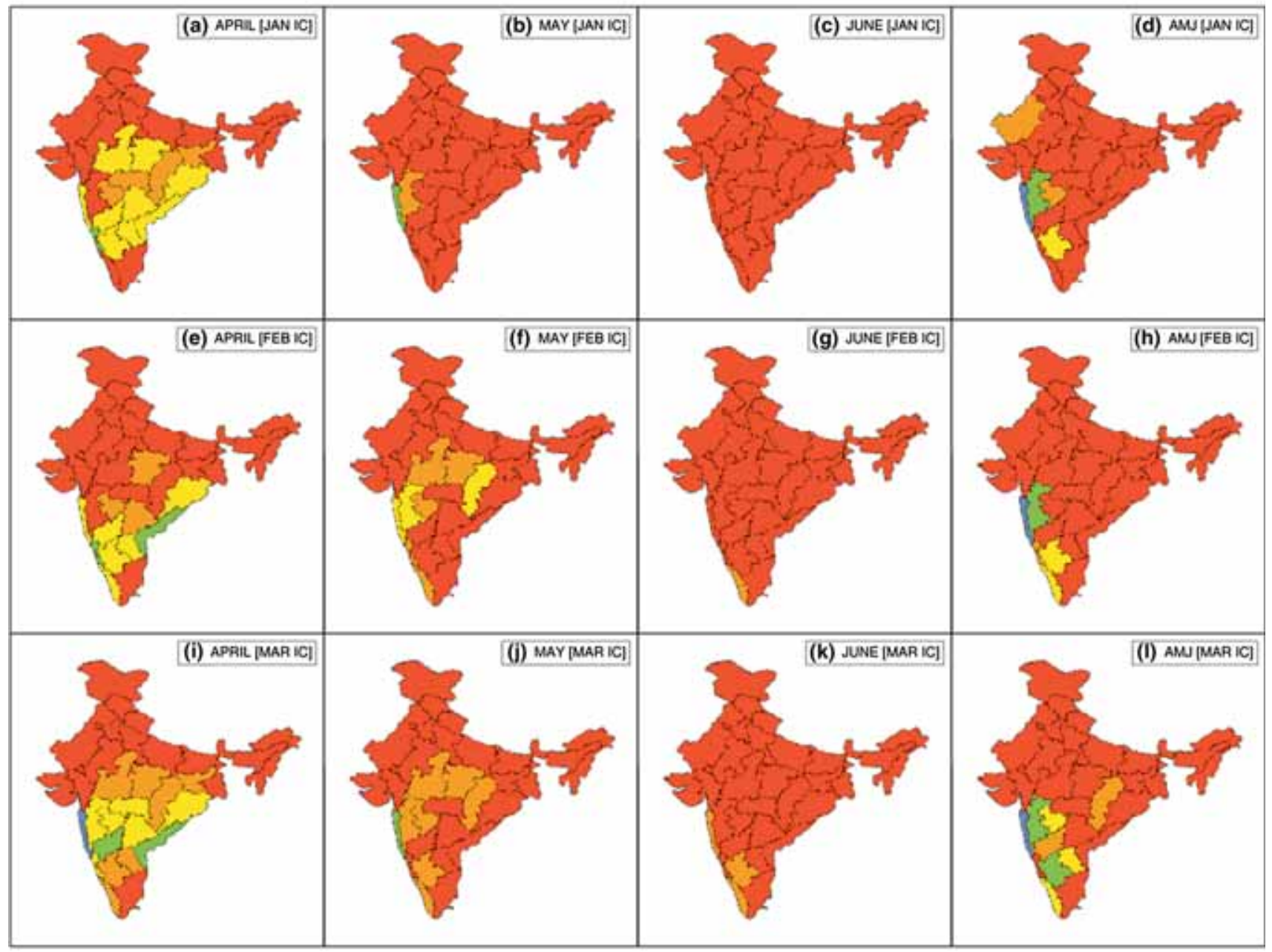

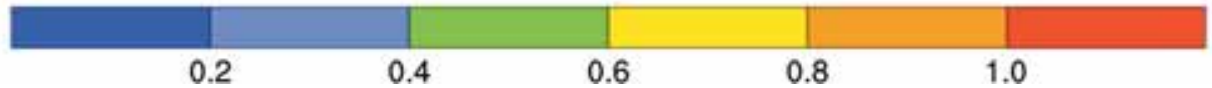

Figure 11. Mean temperature RMSE (in ${ }^{\circ} \mathrm{C}$ ) before bias-correction seen in MMCFS model when compared with IMD observed values using January initial condition for April, May, June and AMJ season as a whole discussed in the first row and similarly using February and March initial conditions in 2nd and 3rd rows, respectively.

(figure 13a, e and i), significance of CC at $\geq 95 \%$ level increases with decrease in lead time from January IC to March IC in which March IC showed CC significant at $\geq 95 \%$ level over most of the sub-divisions of India, except Arunachal Pradesh, Gangetic West Bengal, Rayalaseema and Tamil Nadu and Puducherry. For the May month (figure 13b, f and j), compared to January and March ICs, February IC shows significant CC at $\geq 95 \%$ level over parts of north and central India including Odisha, coastal Andhra Pradesh and Saurashtra and Kutch. For the June month (figure 13c, g and $\mathrm{k}$ ), west coast shows significant $\mathrm{CC}$ at $\geq 95 \%$ level using all three ICs including February IC showing significant CC at $\geq 95 \%$ level over sub-divisions of Gujarat, Madhya Pradesh,
Madhya Maharashtra, Marathwada, Vidarbha and west Rajasthan. For AMJ season (figure 13d, h and 1 ), significance of $\mathrm{CC}$ at $\geq 95 \%$ level increases as lead time decreases; March IC showed CC significant at $\geq 95 \%$ level over western sub-divisions of India, some sub-divisions of central India, northeast India (except Arunachal Pradesh) and Odisha.

\subsection{Hindcast skill of MMCFS country averaged (all India) monthly and seasonal temperatures}

Table 1 shows the CC, RMSE and bias of all India maximum, minimum and mean temperatures before and after statistical bias-correction 
RMSE of MMCFS Hindcast With IMD Observed Mean Temperature (1982-2008) After Statistical Bias Correction
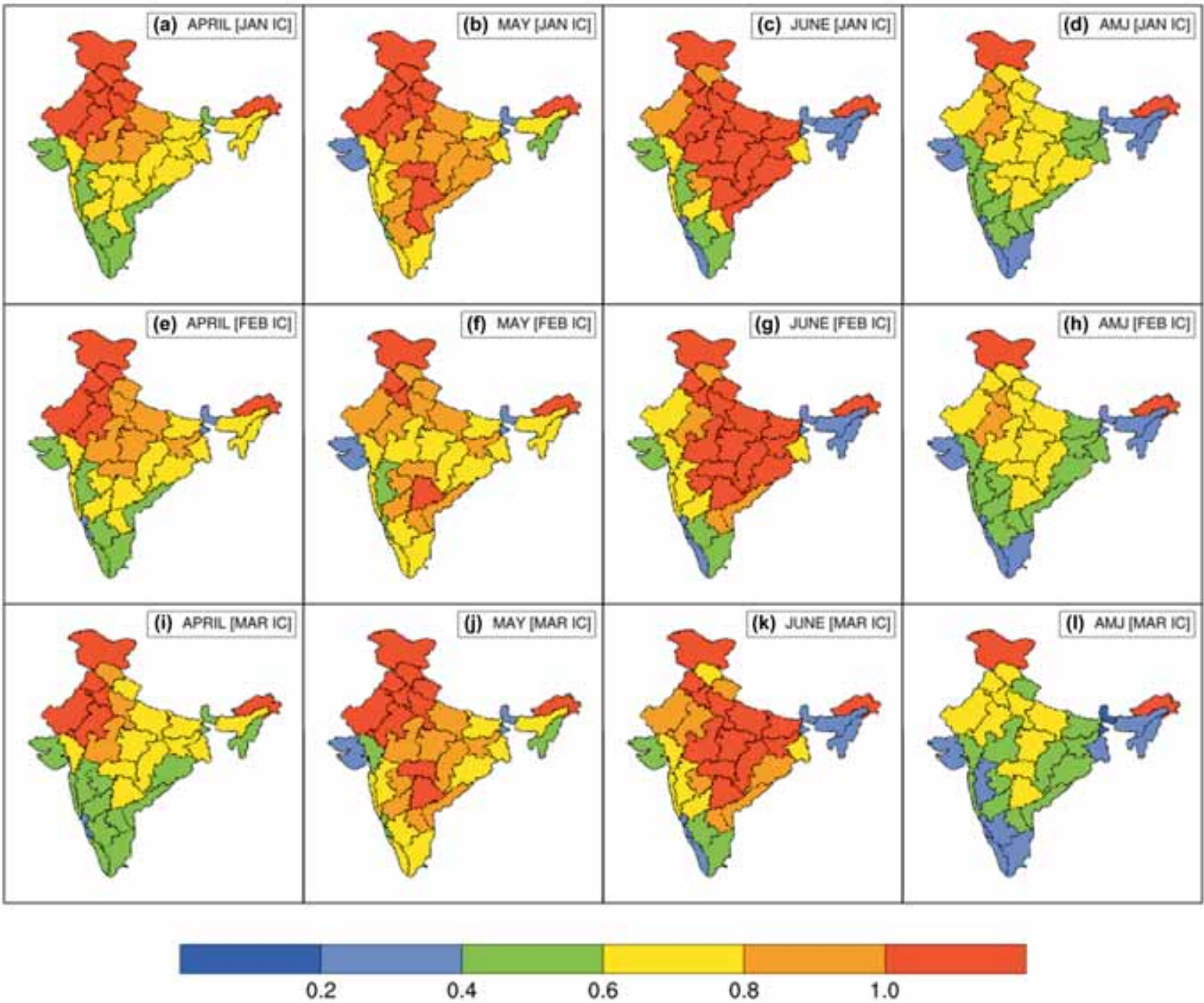

Figure 12. Mean temperature RMSE (in ${ }^{\circ} \mathrm{C}$ ) after bias-correction seen in MMCFS model when compared with IMD observed values using January initial condition for April, May, June and AMJ season as a whole discussed in the first row and similarly using February and March initial conditions in 2nd and 3rd rows, respectively.

for the months of April, May and June and AMJ season using January, February and March ICs computed for the hindcast period of 1982-2008. It is seen that the model shows cold bias in all India averaged maximum, minimum and mean temperatures for the April month using considered ICs before bias-correction and warm bias within 0.09 to $0.16^{\circ} \mathrm{C}$, after bias-correction. In the May month, bias is negative before bias-correction for maximum, minimum and mean temperatures except for January and March ICs for maximum temperature where bias is positive. After biascorrection, bias for maximum, minimum and mean temperature for May month is $0.18,0.1$ and $0.14^{\circ} \mathrm{C}$, respectively. For June month before and after statistical correction bias is positive but the values have decreased for maximum, minimum and mean temperatures from $\sim 2.0$ to $0.19, \sim 0.6$ to 0.12 and $\sim 1.5$ to $0.16^{\circ} \mathrm{C}$, respectively. For AMJ season bias is negative before bias-correction for minimum and mean temperatures and positive for maximum temperature before and after bias-correction. After bias-correction bias for maximum, minimum and mean temperature for AMJ month is $0.18,0.11$ and $0.14^{\circ} \mathrm{C}$, respectively. From table 1, it can be seen that RMSE before and after bias-correction of maximum, minimum and mean temperature for April and June months has decreased from $\geq 1.0$ to $\leq 1.0^{\circ} \mathrm{C}$, for May RMSE before and after bias-correction shows less change. For AMJ season 
Correlation Coefficient Of MMCFS Hindcast and IMD Observed Mean Temperature (1982-2008)
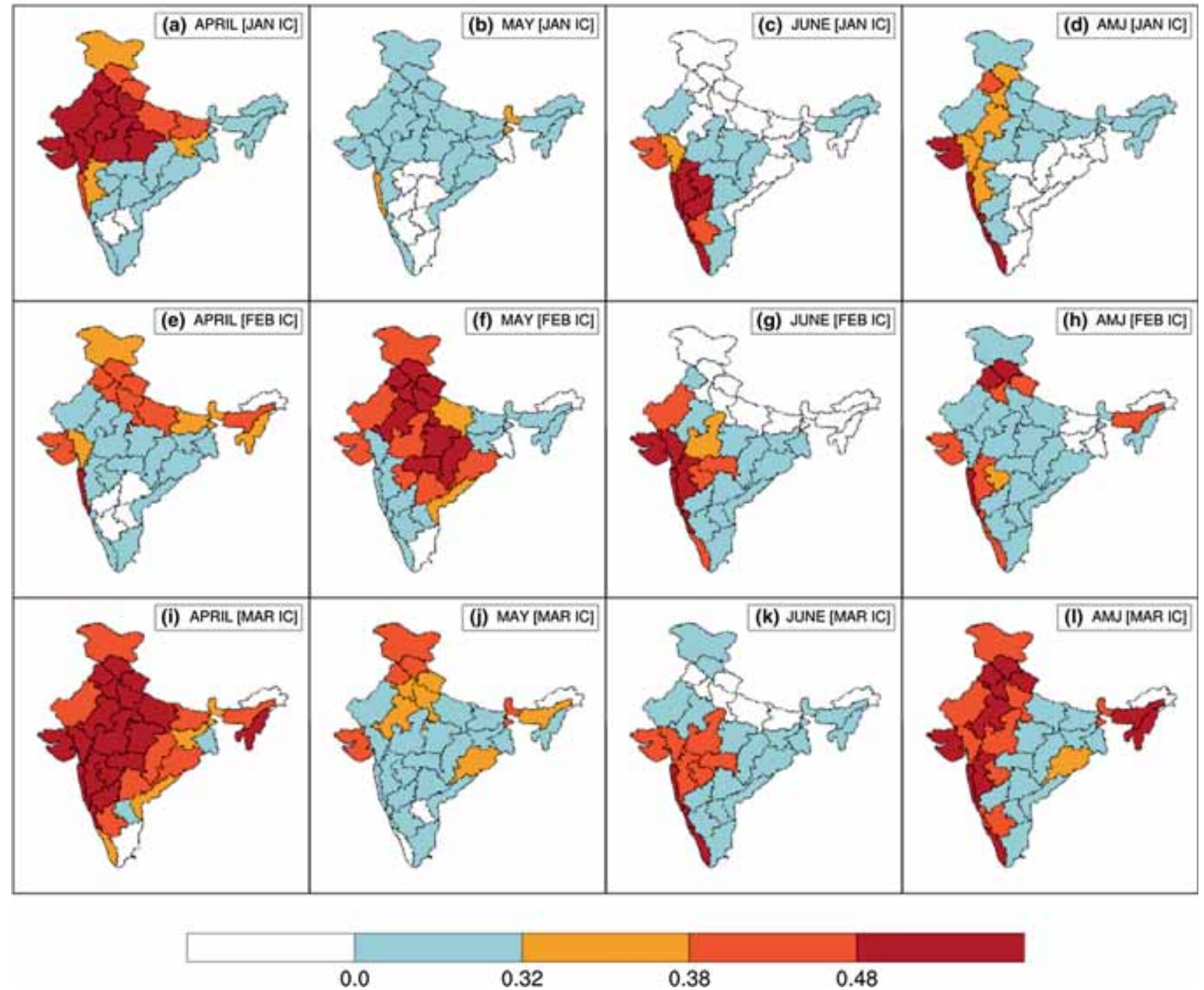

Figure 13. Mean temperature CC (colours indicating white: negative CC, blue: positive less than $90 \%$ level of significance, yellow: positive 90-95\% level of significance, red: positive 95-99\% level of significance and dark red: positive 99\% and above level of significance) of MMCFS with IMD observed for April, May, June months and AMJ season as a whole shown column wise, respectively using January, February and March IC.

RMSE value has decreased half to that observed before bias-correction.

$\mathrm{CC}$ between the all India averaged observed and model maximum, minimum and mean temperatures for the hindcast period (1982-2008) for both with and without model bias-correction were calculated. Through table 1 little difference is seen in CC (significant level of $\geq 95 \%$ shown in bold) before and after bias-correction. For the April month, maximum temperatures show CC significant at $\geq 95 \%$ level using all ICs, minimum and mean temperatures show CC significant at $\geq 95 \%$ level using January and March ICs; with values high for March IC ( 0.6) for maximum, minimum and mean temperatures. For the May month, using February IC maximum, minimum and mean temperatures show CC $(\geq 0.5)$ significant at $\geq 95 \%$ level. For the June month, CC between all India averaged maximum, minimum and mean model and observed temperatures is nowhere significant. For AMJ season CC significant at $\geq 95 \%$ level is seen minimum and mean temperatures using February and March ICs.

It is seen that from table 1 after applying bias-correction, as expected both the bias and RMSE in all India average maximum, minimum and mean temperatures have reduced, but CC have remained more or less same. 
Table 1. All India temperature (maximum, minimum and mean) uncorrected and bias-corrected CC (in bold $95 \%$ significant), RMSE, Bias using MMCFS and IMD observed (1982-2008) for April, May, June and AMJ 2016.

\begin{tabular}{|c|c|c|c|c|c|c|c|c|c|c|}
\hline & & & nuary I & & & ebruary & & & March IC & \\
\hline & & $\mathrm{CC}$ & RMSE & Bias & $\mathrm{CC}$ & RMSE & Bias & $\mathrm{CC}$ & RMSE & Bias \\
\hline April & $T_{\max }$ & 0.49 & 0.99 & -0.67 & 0.43 & 1.26 & -0.97 & 0.63 & 0.91 & -0.64 \\
\hline & $\mathrm{BC} T_{\max }$ & 0.51 & 0.68 & 0.16 & 0.42 & 0.74 & 0.16 & 0.63 & 0.63 & 0.16 \\
\hline & $T_{\min }$ & 0.49 & 1.69 & -1.60 & 0.24 & 1.64 & -1.5 & 0.67 & 1.62 & -1.56 \\
\hline & $\mathrm{BC} T_{\min }$ & 0.53 & 0.52 & 0.09 & 0.27 & 0.61 & 0.09 & 0.65 & 0.46 & 0.08 \\
\hline & $T_{\text {mean }}$ & 0.54 & 1.26 & -1.12 & 0.36 & 1.41 & -1.23 & 0.66 & 1.20 & -1.09 \\
\hline & $\mathrm{BC} T_{\text {mean }}$ & 0.54 & 0.57 & 0.12 & 0.35 & 0.65 & 0.12 & 0.65 & 0.52 & 0.12 \\
\hline May & $T_{\max }$ & 0.17 & 0.94 & 0.09 & 0.47 & 0.73 & -0.09 & 0.25 & 0.88 & 0.22 \\
\hline & $\mathrm{BC} T_{\max }$ & 0.18 & 0.86 & 0.18 & 0.49 & 0.71 & 0.18 & 0.25 & 0.82 & 0.18 \\
\hline & $T_{\min }$ & 0.24 & 1.08 & -0.92 & 0.63 & 0.76 & -0.64 & 0.40 & 0.97 & -0.81 \\
\hline & $\mathrm{BC} T_{\min }$ & 0.23 & 0.56 & 0.11 & 0.65 & 0.42 & 0.11 & 0.42 & 0.52 & 0.11 \\
\hline & $T_{\text {mean }}$ & 0.22 & 0.80 & -0.40 & 0.56 & 0.63 & -0.36 & 0.34 & 0.69 & -0.27 \\
\hline & $\mathrm{BC} T_{\text {mean }}$ & 0.19 & 0.67 & 0.14 & 0.59 & 0.51 & 0.14 & 0.33 & 0.62 & 0.14 \\
\hline June & $T_{\max }$ & 0.09 & 2.68 & 2.44 & 0.22 & 2.29 & 2.03 & 0.25 & 2.25 & 2.0 \\
\hline & $\mathrm{BC} T_{\max }$ & 0.02 & 1.09 & 0.19 & 0.22 & 1.03 & 0.19 & 0.25 & 1.00 & 0.19 \\
\hline & $T_{\min }$ & 0.04 & 0.78 & 0.59 & 0.08 & 0.92 & 0.78 & 0.06 & 0.66 & 0.46 \\
\hline & $\mathrm{BC} T_{\min }$ & 0.06 & 0.47 & 0.12 & 0.13 & 0.45 & 0.13 & 0.17 & 0.44 & 0.13 \\
\hline & $T_{\text {mean }}$ & 0.04 & 1.71 & 1.51 & 0.17 & 1.59 & 1.40 & 0.18 & 1.43 & 1.23 \\
\hline & $\mathrm{BC} T_{\text {mean }}$ & 0.02 & 0.76 & 0.16 & 0.19 & 0.72 & 0.16 & 0.19 & 0.70 & 0.16 \\
\hline AMJ & $T_{\max }$ & 0.003 & 0.95 & 0.61 & 0.11 & 0.75 & 0.33 & 0.27 & 0.81 & 0.54 \\
\hline & $\mathrm{BC} T_{\max }$ & -0.02 & 0.67 & 0.17 & 0.13 & 0.62 & 0.18 & 0.27 & 0.58 & 0.18 \\
\hline & $T_{\min }$ & 0.34 & 0.77 & -0.65 & 0.43 & 0.59 & -0.45 & 0.57 & 0.73 & -0.65 \\
\hline & $\mathrm{BC} T_{\min }$ & 0.35 & 0.39 & 0.10 & 0.43 & 0.37 & 0.11 & 0.58 & 0.33 & 0.11 \\
\hline & $T_{\text {mean }}$ & 0.14 & 0.53 & -0.02 & 0.30 & 0.46 & -0.05 & 0.38 & 0.44 & -0.05 \\
\hline & $\mathrm{BC} T_{\text {mean }}$ & 0.15 & 0.49 & 0.14 & 0.28 & 0.46 & 0.14 & 0.42 & 0.43 & 0.14 \\
\hline
\end{tabular}

Note. BC: Bias corrected.

\section{Verification of temperature forecast for the 2016 April-May-June (AMJ) season}

\subsection{Verification of sub-division averaged maximum, minimum and mean temperatures}

Figure 14 shows MMCFS bias-corrected and IMD observed sub-division averaged maximum temperature anomaly maps of India. The three columns correspond to the MMCFS sub-division averaged bias-corrected maximum temperature forecast anomaly maps of April, May, June and AMJ season based on the January, February and March ICs for 2016. The last row represents the IMD observed maximum temperature anomalies of April, May, June and AMJ season for 2016. In the forecasted maps, the filled circular marks indicate subdivisions having $\mathrm{CC}$ significant at $\geq 95 \%$ level and forecasted anomalies showing same sign as observed anomalies. For the April month, positive anomalies of sub-division averaged maximum temperature were forecasted (figure 14a, e and i) over most of the sub-division using all ICs expect
NMMT, Assam and Meghalaya particularly using March IC, where maximum temperature anomalies are negative. The IMD observed anomaly map for April month (figure $14 \mathrm{~m}$ ) shows positive anomaly for all the sub-divisions except J\&K and SHWB and Sikkim. Forecasted sub-division averaged maximum temperature anomalies for May (figure 14b, $f$ and $j$ ) show positive anomalies over most of the sub-divisions except Assam and Meghalaya (using March IC). The observed maximum temperature anomaly map for May month (figure 14n) shows positive anomalies over most of the subdivisions and sub-division with negative anomalies are J\&K, Himachal Pradesh, Uttarakhand, east Uttar Pradesh, Bihar, SHWB and Sikkim, Assam and Meghalaya, Chhattisgarh and coastal Andhra Pradesh. Forecasted sub-division averaged maximum temperature anomalies for June (figure 14c, g and k) show positive anomalies over most of the sub-divisions and negative anomalies are seen over, coastal Andhra Pradesh (using January IC), SHWB and Sikkim (using February IC), and most of the sub-divisions from the 
MMCFS Forecast and IMD Observed Maximum Temperature Anomaly - 2016

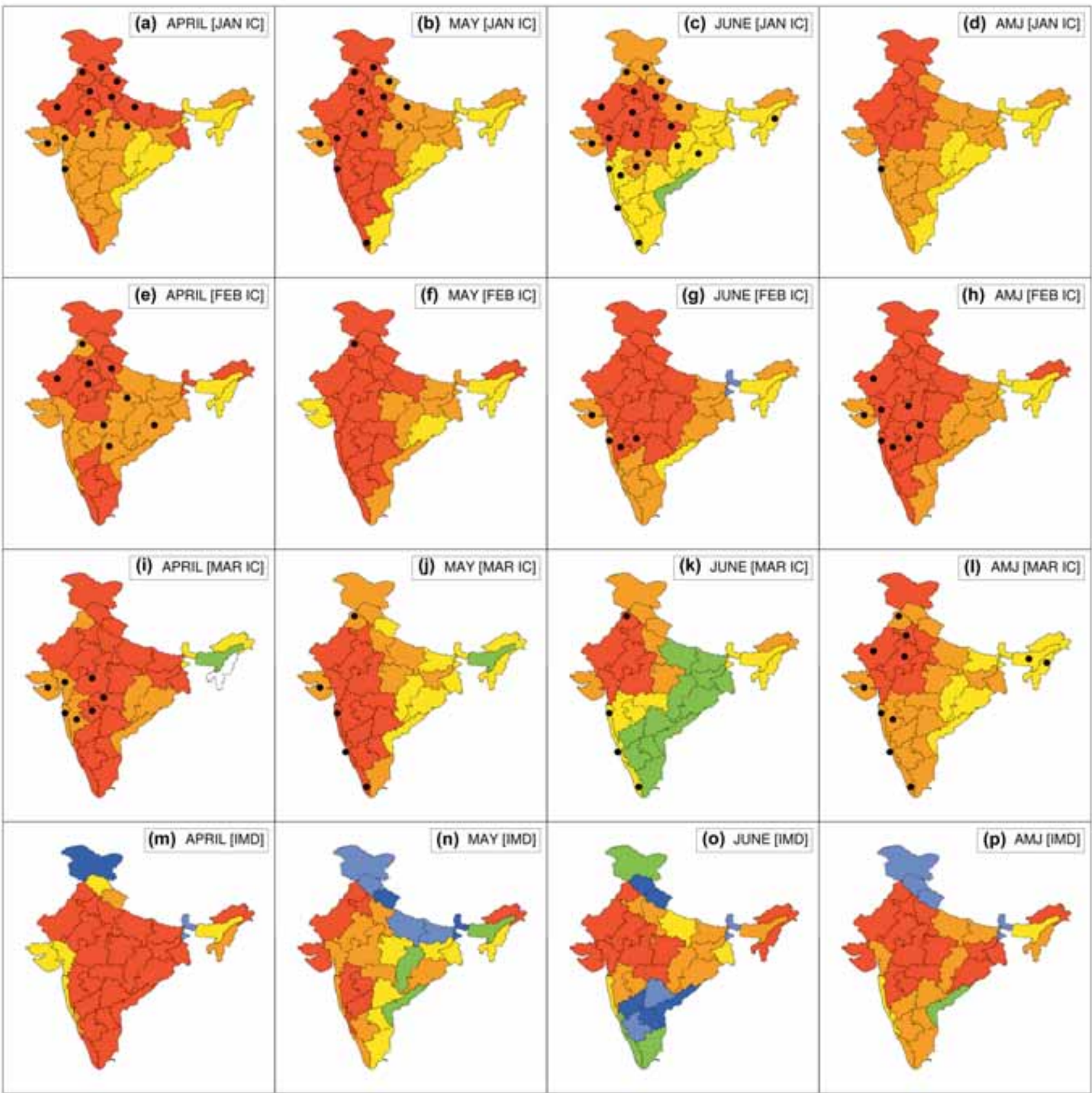

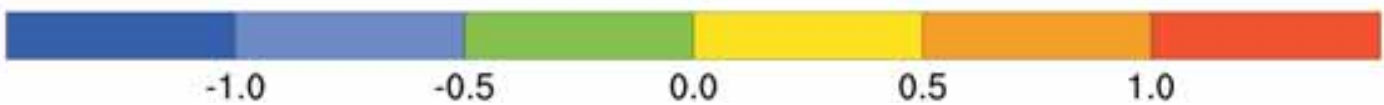

Figure 14. Maximum temperature forecast anomaly (in ${ }^{\circ} \mathrm{C}$ ) for 2016 using January, February and March IC discussed row-wise for April, May, June months and AMJ season as a whole column wise, respectively. Last row representing observed maximum temperature April, May, June and AMJ 2016.

peninsular region (except Kerala), east and east-central India (using March IC) sub-divisions. The observed maximum temperature anomaly map for June (figure 140) shows negative anomalies over sub-divisions Kerala, Tamil Nadu and Pondicherry, coastal Andhra Pradesh, Telangana, Rayalaseema, J\&K, Himachal Pradesh, Uttarakhand, SHWB and Sikkim and sub-divisions of Karnataka, remaining sub-divisions showed positive anomalies. Forecasted sub-division averaged season (AMJ) 
MMCFS Forecast and IMD Observed Minimum Temperature Anomaly - 2016
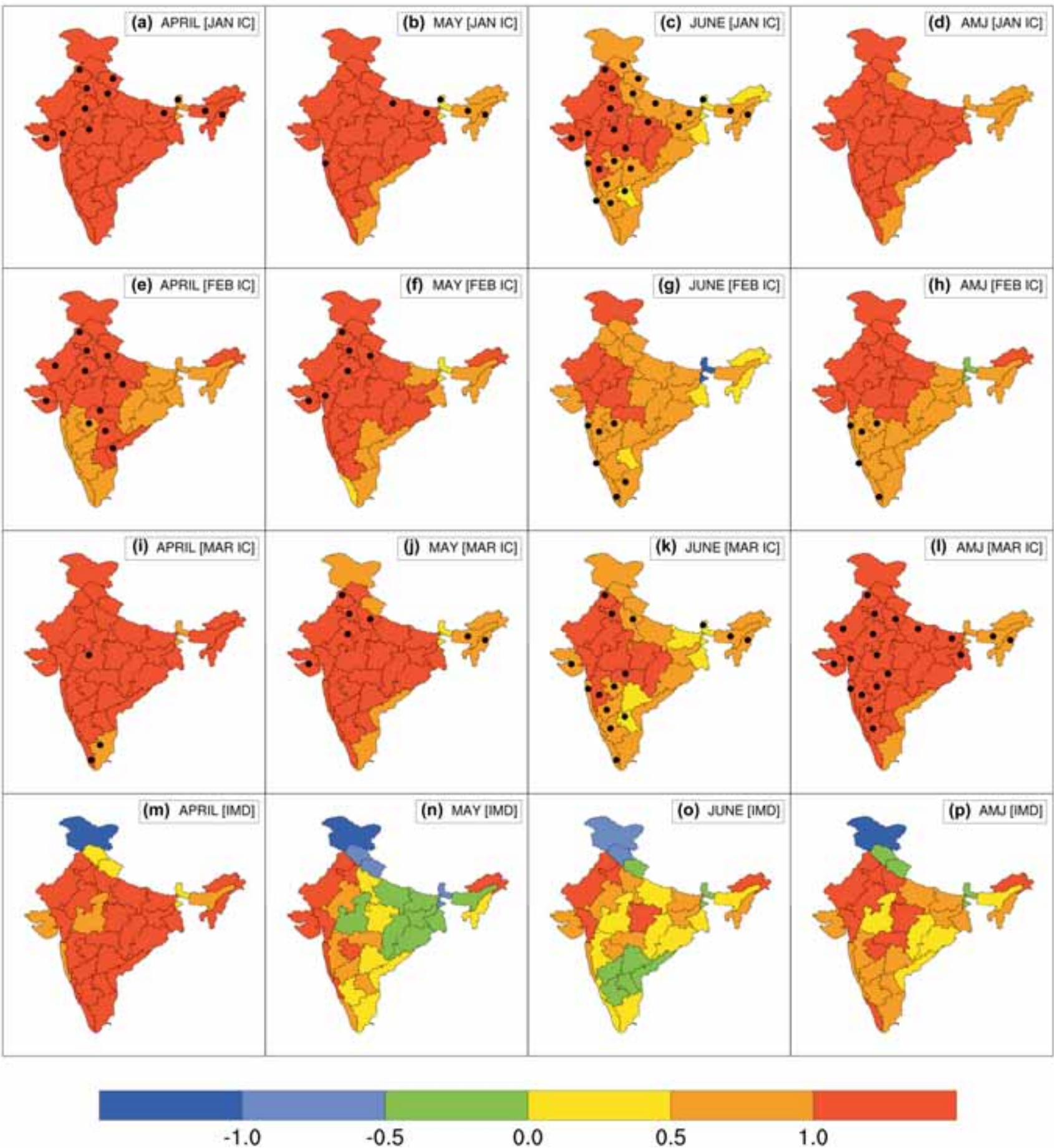

Figure 15. Minimum temperature forecast anomaly (in ${ }^{\circ} \mathrm{C}$ ) for 2016 using January, February and March IC discussed row-wise for April, May, June months and AMJ season as a whole column wise, respectively. Last row representing observed maximum temperature April, May, June and AMJ 2016.

maximum temperature anomalies (figure $14 \mathrm{~d}, \mathrm{~h}$ and l) show positive anomalies over most of the sub-divisions using all ICs. For AMJ season most of the sub-divisions observed (figure 14p) positive anomalies and negative anomalies were observed over coastal Andhra Pradesh, SHWB and Sikkim, J\&K, Himachal Pradesh, and Uttarakhand.

Figure 15 is same as figure 14 for MMCFS bias-corrected and IMD observed sub-division averaged minimum temperature anomaly maps 
MMCFS Forecast and IMD Observed Mean Temperature Anomaly - 2016
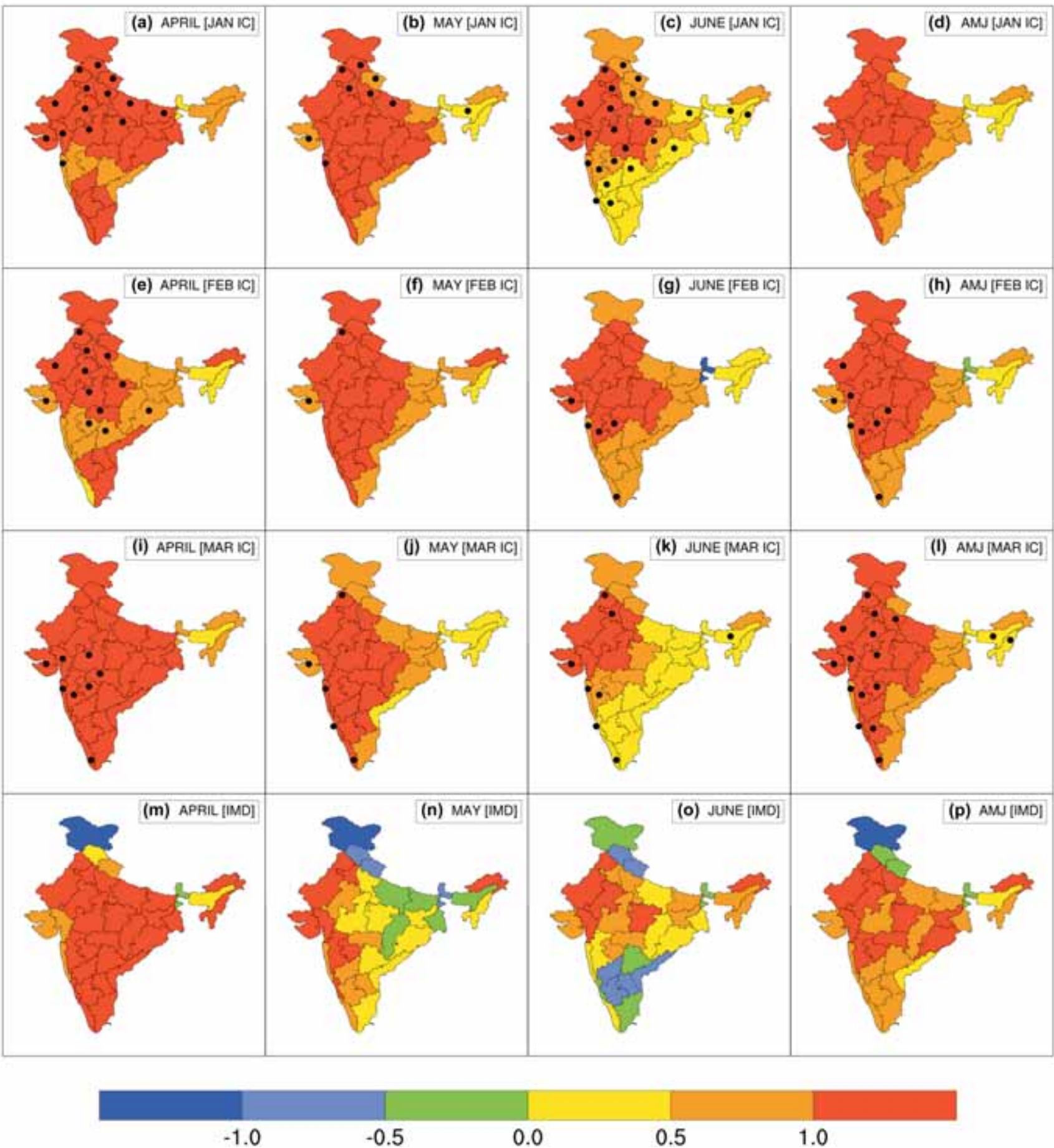

Figure 16. Mean temperature forecast anomaly (in ${ }^{\circ} \mathrm{C}$ ) for 2016 using January, February and March IC discussed row-wise for April, May, June months and AMJ season as a whole column wise, respectively. Last row representing observed maximum temperature April, May, June and AMJ 2016.

of India. It is seen that forecasted sub-division averaged bias-corrected minimum temperature anomalies for April, May, June month and AMJ season are positive using all the three ICs (figure 15a-1) except SHWB and Sikkim sub-division for June month and AMJ season using February
IC (figure 15g). The IMD observed sub-division averaged minimum temperature anomalies is positive for all the sub-divisions (figure $15 \mathrm{~m}-\mathrm{p}$ ) except J\&K for all months and AMJ season, Himachal Pradesh, Uttarakhand, SHWB and Sikkim (during May and June months, and AMJ 
season) (figure 15n-p), west Madhya Pradesh, east Uttar Pradesh, Chhattisgarh, Jharkhand, Bihar, Odisha, Gangetic West Bengal, Assam and Meghalaya (during May month) (figure 15n), North \& South Interior Karnataka and sub-divisions of Andhra Pradesh (during June month) (figure 15o), where observed sub-division averaged minimum temperature anomalies are negative.

Figure 16 is same as figure 14 for MMCFS bias-corrected and IMD observed sub-division averaged mean temperature anomaly maps of India. It is seen that for all the ICs, forecasted sub-division averaged bias-corrected mean temperature anomalies for all the three months and AMJ season are positive over most of the sub-divisions (figure 16a-1) except the forecasted negative anomaly shown over SHWB and Sikkim for June month and AMJ season forecast based on February IC (figure $16 \mathrm{~g}$ and $\mathrm{h}$ ). The observed monthly and season anomaly map of mean temperature (figure $16 \mathrm{~m}-\mathrm{p}$ ) shows positive anomalies over most of the sub-divisions except J\&K and SHWB and Sikkim for all months and season, Himachal Pradesh, Uttarakhand for May, June months and AMJ season (figure 16n-p), east Uttar Pradesh, Bihar, Gangetic West Bengal, Assam and Meghalaya, Chhattisgarh for May month (figure 16n), Tamil Nadu and Puducherry and sub-divisions of Andhra Pradesh and Karnataka for June month (figure 16o).

Table 2 shows the number of sub-divisions showing same signs of anomalies between bias-corrected forecast and observed sub-division averaged temperature (maximum, minimum and mean) based on January, February and March initial conditions. In addition, the pattern correlation (correlation between the bias-corrected forecast and observed sub-division averaged temperature anomalies) is shown. The significant CCs at $95 \%$ level is shown using bold text. From table 2, for the April month, 30-33 sub-divisions showed same sign of anomalies in forecasted and observed sub-division averaged temperature (maximum, minimum and mean) using all the three ICs and there is no significant pattern CC observed. For the May month, around 22 to 26 sub-divisions showed same sign of anomalies using all three ICs with significant pattern CC using March IC for maximum, minimum and mean temperature. For the June month, 22-25 sub-divisions showed same signs of anomalies with significant pattern $\mathrm{CC}$ at 95\% level using January IC (maximum and mean temperatures) and using March IC (maximum, minimum and mean temperatures). For AMJ season, 29-30 sub-divisions showed same signs of anomalies with significant pattern CC at $95 \%$ level using March IC for minimum temperature.

\subsection{Verification of all India monthly and seasonal temperature for the 2016 AMJ season}

Table 3 depicts bias-corrected forecast anomalies of all India averaged maximum, minimum and mean temperature for January, February and March IC for 2016 AMJ season and individual months, along with IMD observed all India averaged maximum, minimum and mean temperature anomalies. In table 3, the bold forecasted figures indicate the case for which model skill CC between model hindcast and observed all India averaged maximum, minimum and mean temperature forecast during the hindcast period is significant at $\geq 95 \%$ level. From table 3 , it is seen that biascorrected forecast for all India averaged maximum, minimum and meantemperature anomalies for all the cases are positive. The ranges of all India averaged maximum temperature forecast anomaly in respect to considered ICs were $0.91-1.06^{\circ} \mathrm{C}$ for April, $0.75-1.21^{\circ} \mathrm{C}$ for May, $0.51-1.14^{\circ} \mathrm{C}$ for June, and $0.78-1.13^{\circ} \mathrm{C}$ for $\mathrm{AMJ}$ season. The ranges of all India averaged minimum temperature anomaly forecast in respect to considered ICs are 1.03$2.06^{\circ} \mathrm{C}$ for April, $1.28-1.43^{\circ} \mathrm{C}$ for May, $0.79-0.94^{\circ} \mathrm{C}$ for June, and $1.04-1.46^{\circ} \mathrm{C}$ for AMJ season. The ranges of all India averaged mean temperature anomaly forecast in respect to considered ICs are $1.07-1.61^{\circ} \mathrm{C}$ for April, $1.06-1.26^{\circ} \mathrm{C}$ for May, 0.72 $0.93^{\circ} \mathrm{C}$ for June, and $1.09-1.14^{\circ} \mathrm{C}$ for AMJ season. IMD observed all India averaged maximum temperature anomalies for the months of April, May, June and the AMJ season were 1.50, 0.56, 0.54, and $0.92^{\circ} \mathrm{C}$, respectively. For April, the observed value was well above the highest forecasted value among all ICs and thus the forecast was an underestimate of the realized temperature. India Meteorological Department observed all India averaged minimum temperature anomalies for the months of April, May, June months and AMJ season were 1.31, 0.37, 0.44 , and $0.77^{\circ} \mathrm{C}$, respectively indicating April was the warmest among all the 3 months. Thus except for the month of April, the observed all India averaged minimum temperature anomalies were not within the range of forecasts based on considered ICs (all the forecasts were higher than the observed all India minimum temperature 
Table 2. Number of sub-divisions with same sign of bias-corrected forecast and observed anomalies April, May, June and AMJ 2016 with pattern CC (in bold 95\% significant) using MMCFS and IMD observed (1982-2008) for April, May, June and AMJ 2016.

\begin{tabular}{|c|c|c|c|c|c|c|c|}
\hline & & \multicolumn{2}{|c|}{ January IC } & \multicolumn{2}{|c|}{ February IC } & \multicolumn{2}{|c|}{ March IC } \\
\hline & & $\begin{array}{c}\text { No. of } \\
\text { subdivision }\end{array}$ & $\mathrm{CC}$ & $\begin{array}{c}\text { No. of } \\
\text { subdivision }\end{array}$ & $\mathrm{CC}$ & $\begin{array}{c}\text { No. of } \\
\text { subdivision }\end{array}$ & $\mathrm{CC}$ \\
\hline \multirow[t]{3}{*}{ April } & $T_{\max }$ & 32 & -0.23 & 32 & -0.29 & 30 & 0.12 \\
\hline & $T_{\min }$ & 33 & 0.22 & 33 & -0.14 & 33 & 0.33 \\
\hline & $T_{\text {mean }}$ & 32 & -0.02 & 32 & -0.25 & 32 & 0.27 \\
\hline \multirow[t]{3}{*}{ May } & $T_{\max }$ & 25 & 0.28 & 25 & 0.005 & 26 & 0.38 \\
\hline & $T_{\min }$ & 22 & 0.29 & 22 & 0.06 & 22 & 0.39 \\
\hline & $T_{\text {mean }}$ & 24 & 0.35 & 24 & 0.07 & 24 & 0.45 \\
\hline \multirow[t]{3}{*}{ June } & $T_{\max }$ & 23 & 0.53 & 23 & 0.19 & 22 & 0.45 \\
\hline & $T_{\min }$ & 25 & 0.31 & 26 & 0.22 & 25 & 0.39 \\
\hline & $T_{\text {mean }}$ & 23 & 0.53 & 24 & 0.19 & 23 & 0.51 \\
\hline \multirow[t]{3}{*}{ AMJ } & $T_{\max }$ & 29 & 0.04 & 29 & -0.13 & 29 & 0.12 \\
\hline & $T_{\min }$ & 30 & 0.31 & 31 & 0.10 & 30 & 0.38 \\
\hline & $T_{\text {mean }}$ & 30 & 0.24 & 31 & 0.02 & 30 & 0.34 \\
\hline
\end{tabular}

Table 3. All India temperature (maximum, minimum and mean) anomaly bias-corrected forecasts (bold 95\% significant) using MMCFS and IMD observed for April, May, June and AMJ 2016.

\begin{tabular}{|c|c|c|c|c|c|c|c|c|c|c|c|c|}
\hline & \multicolumn{3}{|c|}{ Maximum temperature } & \multirow{2}{*}{$\begin{array}{l}\text { IMD } \\
2016\end{array}$} & \multicolumn{3}{|c|}{ Minimum temperature } & \multirow{2}{*}{$\begin{array}{l}\text { IMD } \\
2016\end{array}$} & \multicolumn{3}{|c|}{ Mean temperature } & \multirow{2}{*}{$\begin{array}{l}\text { IMD } \\
2016\end{array}$} \\
\hline & Jan IC & Feb IC & Mar IC & & Jan IC & Feb IC & Mar IC & & Jan IC & Feb IC & Mar IC & \\
\hline April & 0.91 & 1.03 & 1.06 & 1.50 & 1.58 & 1.03 & 2.06 & 1.31 & 1.28 & 1.07 & 1.61 & 1.49 \\
\hline May & 0.97 & 1.21 & 0.75 & 0.56 & 1.43 & 1.28 & 1.39 & 0.37 & 1.21 & 1.26 & 1.06 & 0.42 \\
\hline June & 0.65 & 1.14 & 0.51 & 0.54 & 0.92 & 0.79 & 0.94 & 0.44 & 0.78 & 0.93 & 0.72 & 0.54 \\
\hline AMJ & 0.84 & 1.13 & 0.78 & 0.92 & 1.31 & 1.04 & 1.46 & 0.77 & 1.09 & 1.09 & 1.14 & 0.85 \\
\hline
\end{tabular}

anomaly). India Meteorological Department observed all India averaged mean temperature anomalies for the months of April, May, June month and the AMJ season were 1.49, 0.42, 0.54 , and $0.85^{\circ} \mathrm{C}$, respectively, indicating April was warmest among all the 3 months and except for the month of April, the observed all India averaged mean temperature anomalies were not within the range of forecasts based on considered ICs (all the forecasts were higher than the observed all India mean temperature anomaly).

\section{Conclusions}

The monthly and seasonal maximum, minimum and mean temperature simulations over India from the monsoon mission climate forecasting system (MMCFS) for the hindcast period of 1982-2008 and forecast for 2016 were analyzed to examine the skill of the model at the sub-division and all India scales for the hot weather season of April-June (AMJ). The model hindcasts and forecasts were prepared using initial conditions January, February and March. The model hindcasts and forecast for 2016 were bias-corrected using IMD high resolution daily gridded temperature data over India. Statistical bias-correction based on the quantile-based mapping method at the grid point level was used for the purpose.

From the study, the following conclusions can be derived

(i) For all three ICs and during all the months of the AMJ, four sub-divisions (J\&K, Himachal Pradesh, Uttarakhand, and Arunachal Pradesh) showed bias $\leq-2^{\circ} \mathrm{C}$.

(ii) For all three ICs, cold bias was observed in all India averaged maximum temperature for April, in minimum temperature for April, May, and AMJ, and in the mean temperature (April and May).

(iii) The grid point level statistical bias-correction was successful in reducing the bias and RMSE of the MMCFS model hindcasts at the sub-division and all India scales. 
(iv) For maximum, minimum and mean temperatures, in general, hindcast based on the February and March ICs showed the highest number of sub-divisions with significant skill. Among the various months of the AMJ season, April had the highest number of subdivisions with significant model hindcast skill. These sub-divisions were mainly from northwest India and neighboring central India and along the west coast.

(v) For the all India temperature also March IC based forecast showed highest skill for all the months and AMJ season followed by February IC.

(vi) The verification of the 2016 monthly and seasonal bias-corrected temperature forecast for the AMJ season showed that model was able to indicate a correct sign of the temperature anomalies in most of the sub-divisions though there were differences in the magnitudes of forecasted and temperature anomalies. Overall, the March IC based forecast could predict the monthly and season temperature patterns during the 2016 AMJ with significant pattern anomaly correlation. The pattern anomaly correlations for the May and June forecasts based on March IC were significant at $\geq 95 \%$ ).

\section{Acknowledgements}

Authors thank Dr M Rajeevan, Secretary, MoES, Dr K J Ramesh, DGM, IMD and Dr A K Sahai, Head, CRS, IMD, Pune for their encouragement and support in completing the work and we also thank Dr Soma Sen Roy for her valuable suggestions. Special thanks to anonymous reviewers for their valuable comments which helped us understand our scope of improvement in this research paper.

\section{References}

Becker J A and Stewart L K 2011 Heat-related illness; Am. Fam. Physician 83(11) 1325-1330.

Cayan D R, Maurer E P, Dettinger M D, Tyree M and Hayhoe K 2008 Climate change scenarios for the California region; Clim. Change $\mathbf{8 7 ( 1 )} 21-42$.

Disastrous Weather Events (DWE) Annual Reports 2013, 2014, 2015, 2016 (India Meteorological Department publication).
Filippini M and Pachauri S 2004 Elasticities of electricity demand in urban Indian households; Energy Policy 32(3) 429-436.

Fortmann-Roe S 2012 Understanding the bias-variance trade off; http://scott.fortmann-roe.com/docs/BiasVariance. html.

Ines A V M and Hansen J W 2006 Bias correction of daily GCM rainfall for crop simulation studies; Agr. Forest Meteorol. 138 44-53.

Kothawale D R, Munot A A and Kumar K K 2010 Surface air temperature variability over India during 1901-2007, and its association with ENSO; Climate Res. 42(2) 89-104.

Li H, Sheffield J and Wood E F 2010 Bias correction of monthly precipitation and temperature fields from Intergovernmental Panel on Climate Change AR4 models using equidistant quantile matching; J. Geophys. Res. (Atmos.) 115(D10), https://doi.org/10.1029/2009JD012882.

Maurer E P and Hidalgo H G 2008 Utility of daily vs. monthly large-scale climate data: An intercomparison of two statistical downscaling methods; Hydrol. Earth Syst. Sci. 12 551-563.

Pachauri R K, Allen M R, Barros V R, Broome J, Cramer W and Christ R et al. 2014 Climate change 2014: Synthesis report. Contribution of Working Groups I, II and III to the fifth assessment report of the Intergovernmental Panel on Climate Change, IPCC, 151p.

Pai D S, Nair S A and Ramanathan A N 2013 Long term climatology and trends of heat waves over India during the recent 50 years (1961-2010); Mausam 64(4) 585-604.

Panofsky H A and Brier G W 1958 Some applications of statistics to meteorology; Mineral Industries Extension Services, College of Mineral Industries, Pennsylvania State University.

Piani C, Haerter J O and Coppola E 2010 Statistical bias correction for daily precipitation in regional climate models over Europe; Theor. Appl. Climatol. 99(1-2) 187-192.

Ramu D A, Sabeerali C T, Chattopadhyay R, Nagarjuna Rao D, George G, Dhakate A R, Salunke K, Srivastava A and Rao S A 2016 Indian summer monsoon rainfall simulation and prediction skill in the CFSv2 coupled model: Impact of atmospheric horizontal resolution; J. Geophys. Res. (Atmos.) 121(5) 2205-2221.

Sivakumar M V K, Das H P and Brunini O 2005 Impacts of present and future climate variability and change on agriculture and forestry in the arid and semi-arid tropics; Clim. Change 70(1-2) 31-72.

Srivastava A K, Rajeevan M and Kshirsagar S R 2009 Development of a high resolution daily gridded temperature data set (1969-2005) for the Indian region; Atmos. Sci. Lett. 10(4) 249-254.

Valor E, Meneu V and Caselles V 2001 Daily air temperature and electricity load in Spain; J. App. Meteorol. 40(8) 1413-1421.

Wood A W, Leung L R, Sridhar V and Lettenmaier D P 2004 Hydrologic implications of dynamical and statistical approaches to downscaling climate model outputs; Clim. Change 62(1-3) 189-216. 